\title{
Regulation of the X Chromosomes in Caenorhabditis elegans
}

\author{
Susan Strome1, William G. Kelly², Sevinc Ercan³ ${ }^{3}$ and Jason D. Lieb ${ }^{4}$ \\ ${ }^{1}$ Department of Molecular, Cell and Developmental Biology, University of California, Santa Cruz, \\ Santa Cruz, California 95064; ${ }^{2}$ Department of Biology, Emory University, Atlanta, Georgia 30322; \\ ${ }^{3}$ Department of Biology and Center for Genomics and Systems Biology, New York University, New York, New York \\ 10003; ${ }^{4}$ Department of Biology and Carolina Center for Genome Sciences, The University of North Carolina at Chapel \\ Hill, Chapel Hill, North Carolina 27599 \\ Correspondence: sstrome@ucsc.edu
}

\section{SUMMARY}

Dosage compensation, which regulates the expression of genes residing on the sex chromosomes, has provided valuable insights into chromatin-based mechanisms of gene regulation. The nematode Caenorhabditis elegans has adopted various strategies to down-regulate and even nearly silence the X chromosomes. This article discusses the different chromatin-based strategies used in somatic tissues and in the germline to modulate gene expression from the $C$. elegans $X$ chromosomes and compares these strategies to those used by other organisms to cope with similar $\mathrm{X}$-chromosome dosage differences.

\section{Outline}

1 Sex chromosome imbalance in C. elegans

2 Assessing the $\mathrm{X}: \mathrm{A}$ ratio

3 The dosage compensation complex (DCC) resembles the condensin complex

4 Recruitment and spreading of the DCC

5 Effects of the DCC: Down-regulation of X-linked genes and the autosomal gene her1

6 Compensatory up-regulation of X-linked genes
7 Germline development and global repression of the $\mathrm{X}$ chromosomes

8 Meiotic silencing of the single $\mathrm{X}$ in males

9 Regulation of X-chromosome repression by the MES histone modifiers

10 Paternal $\mathrm{X}$ inactivation in early embryos

11 Concluding remarks

References

Editors: C. David Allis, Marie-Laure Caparros, Thomas Jenuwein, and Danny Reinberg

Additional Perspectives on Epigenetics available at www.cshperspectives.org

Copyright (C 2014 Cold Spring Harbor Laboratory Press; all rights reserved; doi: 10.1101/cshperspect.a018366

Cite this article as Cold Spring Harb Perspect Biol 2014;6:a018366 


\section{OVERVIEW}

Dosage compensation, which regulates the expression of genes residing on the sex chromosomes, has provided valuable insights into epigenetic mechanisms used to regulate whole chromosomes. The nematode Caenorhabditis elegans has adopted various strategies to down-regulate and even silence the $\mathrm{X}$ chromosomes. This article discusses the different chromatin-based strategies used in somatic tissues and in the germline to modulate gene expression from the $C$. elegans $X$ chromosomes, and compares these strategies to those used by other organisms to cope with similar X-chromosome dosage differences.

Why is dosage compensation necessary? The mechanism of sex determination in $C$. elegans relies on the ratio of $X$ chromosomes to sets of autosomes (X:A ratio). Diploid animals with two $X$ chromosomes (X:A ratio of 1$)$ develop as hermaphrodites, whereas those with one $X$ chromosome (X:A ratio of 0.5 ) develop as males. The difference in $\mathrm{X}$ chromosome dosage between the sexes, if not rectified, leads to imbalanced expression of X-linked genes and to lethality in one sex. Thus, equalizing expression of $X$ linked genes between the sexes is one function of dosage compensation.

In the somatic tissues of worms, dosage compensation occurs by down-regulating transcription approximately twofold from each of the two $X$ chromosomes in the $X X$ sex. This down-regulation is accomplished by the dosage compensation complex (DCC), a constellation of proteins assembled specifically on the $\mathrm{X}$ chromosomes of XX animals. The protein components of the DCC are homologous to members of the condensin complex, which is required for chromosome condensation and segregation during mitosis and meiosis. The similarity between the DCC and condensin complexes has led to the hypothesis that the DCC achieves repression of X-linked genes by partially condensing the X chromosomes. Long-standing questions surrounding dosage compensation in $C$. elegans include how the $\mathrm{X}$ : A ratio is assessed, how the DCC is assembled uniquely in $X X$ animals, how the DCC is targeted to the $X$ chromosomes, and the mechanism by which it accomplishes twofold down-regulation of $X$-linked gene expression. This article summarizes the substantial progress that has been made in answering these key questions.
The dosage compensation strategy used by $C$. elegans differs from the strategies used by mammals and fruit flies (Drosophila). Mammals achieve dosage compensation by globally silencing one $X$ in the female $(X X)$ sex. Fruit flies up-regulate gene expression from the single $X$ in the male $(X Y)$ sex. This diversity of strategies probably reflects the co-option of different preexisting general chromatin mechanisms for the specialized role of equalizing $\mathrm{X}$ gene expression between sexes.

In addition to mechanisms that equalize gene dosage between sexes, there is strong evidence that these organisms also correct the chromosome dosage imbalance within cells, which is caused by a single dose of $\mathrm{X}$-linked expression versus biallelic autosomal expression. In $C$. elegans and mammals, this is achieved by up-regulation of expressed X-linked genes in both sexes. Thus, in C. elegans hermaphrodites and mammalian females, down-regulation of the $X$ via dosage compensation mechanisms is superimposed on this general upregulation.

In the germline tissue (i.e., the reproductive cells) of worms, a more extreme modulation of X-linked gene expression occurs. Transcription from the single $X$ in males and both $X s$ in hermaphrodites is significantly repressed in proliferating and meiotic germ cells. In germ cells of both sexes, the $X$ chromosomes lack histone modifications that are associated with actively expressed chromatin. This is regulated at least in part by the MES proteins, chromatin modifiers whose loss leads to sterility. Furthermore, in males, the single $\mathrm{X}$ chromosome in each germ nucleus acquires histone modifications that are associated with heterochromatic silencing. This silencing depends on the unpaired status of the X in male meiosis. Genes expressed in the germline are strikingly underrepresented on the $\mathrm{X}$ chromosome. A favored view is that heterochromatinization of the unpaired $X$ in male meiotic germ cells led to selection against $X$ linkage of genes required for essential germline functions. In addition, the equalization of X-linked gene expression between the sexes may also be required in germ cells, and the most straightforward way to achieve this may have been to repress both $X$ chromosomes in the XX sex. Thus, the $C$. elegans germline continues to be a critical system to explore how chromosome imbalances between the sexes have led to epigenetic regulation of chromosome states and gene expression. 


\section{SEX CHROMOSOME IMBALANCE}

IN C. elegans

C. elegans exists as two sexes that are genetically distinguished by their $\mathrm{X}$-chromosome complement. XX worms are hermaphrodites and $\mathrm{XO}$ worms are males. There is no sex-specific chromosome, such as a Y chromosome. Hermaphrodites and males display numerous sex-specific anatomical features and have different germline developmental programs (Fig. 1). These dramatic differences between the sexes are initiated in the early embryo, and result from counting and properly responding to the number of $\mathrm{X}$ chromosomes relative to autosomes (Nigon 1951; reviewed in Meyer 2000). How can a simple difference in sex chromosome number translate into such dramatically different developmental programs? An important concept is that C. elegans cells must assess not only the number of $\mathrm{X}$ chromosomes but also the number of sets of autosomes. It is the ratio of these- the X:A ratio- that determines sex. Diploid animals with two X chromosomes (X:A ratio of 1) develop as hermaphrodites, whereas those with one $\mathrm{X}$ chromosome (X:A ratio of 0.5) develop as males (Fig. 2). Many of the mechanistic details of appropriately responding to the X:A ratio have been elegantly dissected and are summarized in Sections 3-5.

The difference in X-chromosome dosage between the sexes leads, if uncorrected, to a difference in the levels of $\mathrm{X}$-linked gene expression. Indeed, the double dose of $\mathrm{X}$ genes is lethal to hermaphrodites if not corrected. Intriguingly, somatic cells and germ cells have evolved different mechanisms to deal with this X-dosage challenge (Fig. 3). The germline and somatic lineages are fully separated from each other by the 24-cell stage of embryogenesis. Starting at about the 30-cell stage, the somatic lineages initiate a process termed "dosage compensation" whereby genes that reside on the $\mathrm{X}$ chromosomes of XX animals are downregulated approximately twofold. In contrast, as discussed in Brockdorff and Turner (2014) and Kuroda and Lucchesi (2014), mammals implement dosage compensation by globally silencing one $\mathrm{X}$ in the XX sex, and fruit flies implement dosage compensation by up-regulating expression from the single X in the XY sex. In C. elegans germline tissue, a more extreme adjustment of X-linked gene expression occurs: The single $\mathrm{X}$ in males and both Xs in hermaphrodites are globally repressed. The chromatin-based mechanisms that accomplish dosage compensation in the soma and X-chromosome repression in the germline are the subjects of this article.

\section{ASSESSING THE X:A RATIO}

How do worm cells count Xs and autosomes so that dosage compensation is implemented when the $\mathrm{X}$ :A ratio is 1 ? Four small regions of the X, termed X signal elements (XSEs), have been identified as contributing to the numerator portion of the X:A ratio. By mutagenesis, four responsible Xlinked genes have been identified within the XSE regions: sex-1 (sex for signal element on $\mathrm{X}$ ), fox-1 (fox for feminizing gene on X), ceh-39, and sex-2 (Carmi et al. 1998; Skipper et al. 1999; Gladden and Meyer 2007; Gladden et al. 2007). These four genes repress expression of xol-1, the most upstream gene in the sex determination and dosage compensation pathway, during a critical window of embryonic

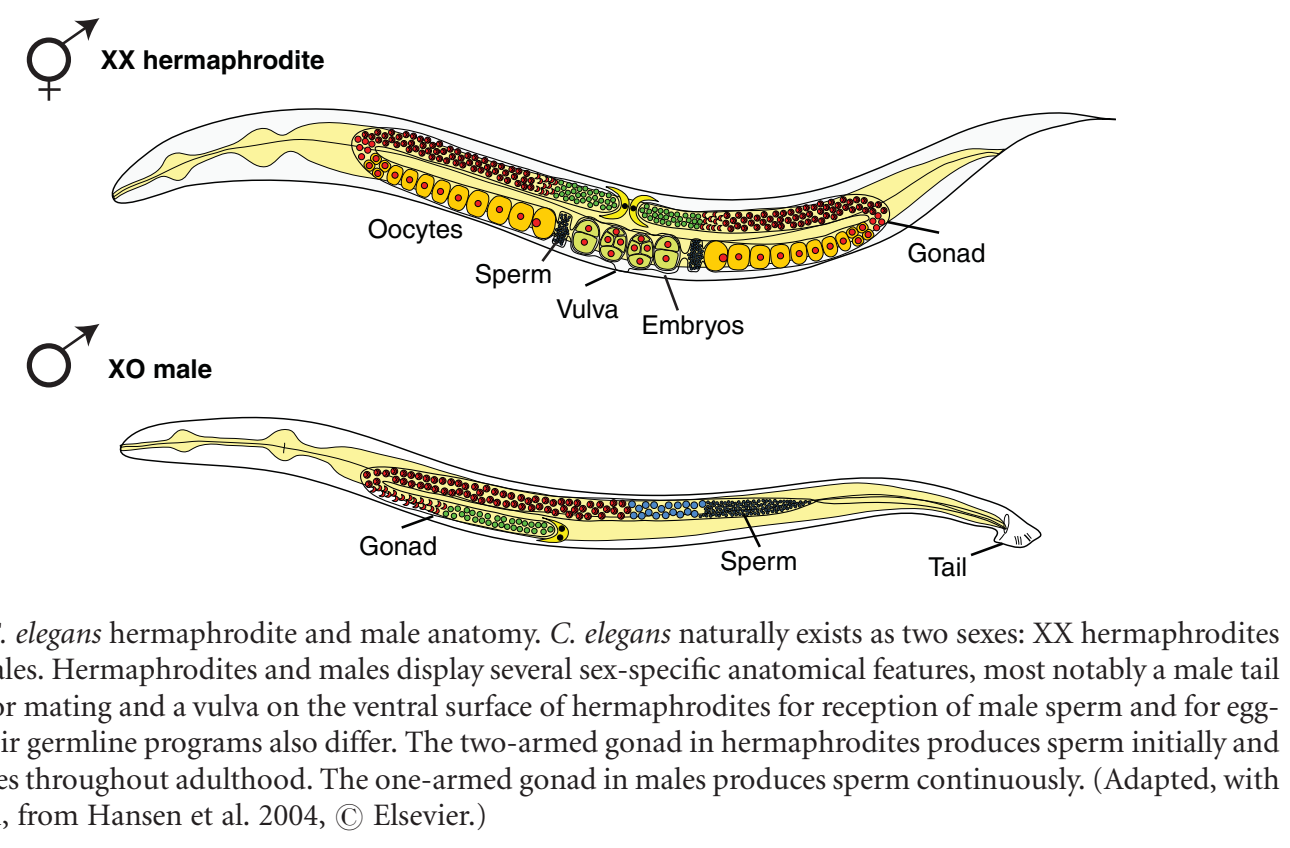

Figure 1. C. elegans hermaphrodite and male anatomy. C. elegans naturally exists as two sexes: XX hermaphrodites and XO males. Hermaphrodites and males display several sex-specific anatomical features, most notably a male tail designed for mating and a vulva on the ventral surface of hermaphrodites for reception of male sperm and for egglaying. Their germline programs also differ. The two-armed gonad in hermaphrodites produces sperm initially and then oocytes throughout adulthood. The one-armed gonad in males produces sperm continuously. (Adapted, with permission, from Hansen et al. 2004, (C) Elsevier.) 
S. Strome et al.

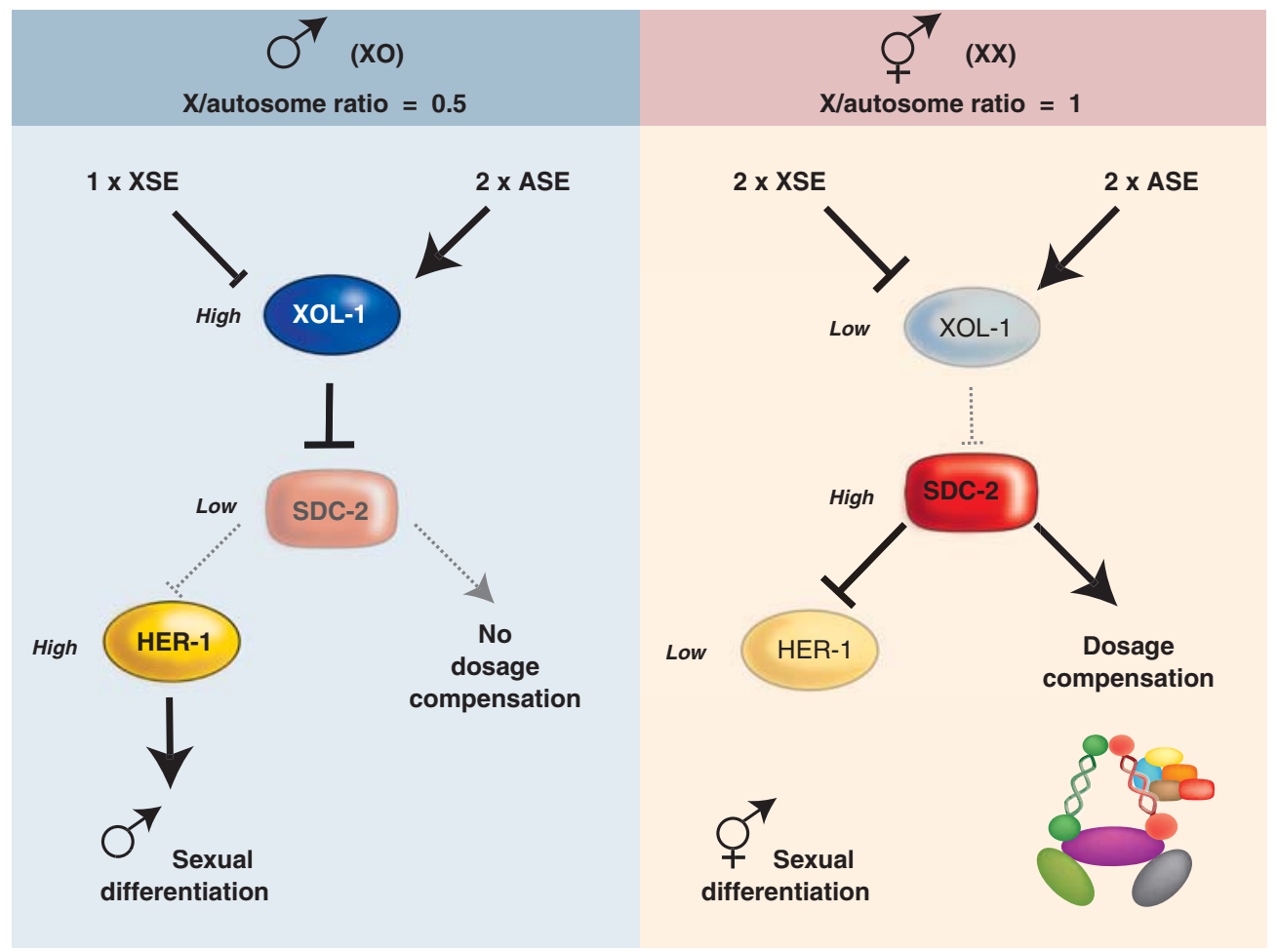

Figure 2. Pathway of sex determination and dosage compensation in C. elegans. The proposed roles of $\mathrm{X}$ signal elements (XSEs) and autosomal signal elements (ASEs) in regulating XOL-1 levels and the subsequent sexual differentiation and assembly of the dosage compensation complex (DCC), which represses X-linked gene expression about twofold in XX hermaphrodites, are highlighted.

development (Fig. 2). Because XX embryos produce approximately twice as much SEX-1, SEX-2, CEH-39, and FOX-1 as XO embryos, xol-1 expression is much lower in $\mathrm{XX}$ than in XO embryos. One of the XSE genes, SEX-1, is a nuclear hormone receptor, which represses transcription of xol-1 (Carmi et al. 1998). FOX-1 is an RNA-binding protein that reduces the level of XOL-1 protein through unknown posttranscriptional mechanisms (Nicoll et al. 1997; Skipper et al. 1999; Gladden et al. 2007). CEH-39 has a predicted DNA-binding domain that is similar to the ONECUT family of homeobox-containing transcription factors. CEH-39 does not contain sequence similarity to ONECUT proteins outside the DNA-binding domain (Gladden and Meyer 2007). Reducing the level of individual XSEs has a small effect on sex determination. Combined reductions have a larger effect, suggesting that the XSEs act cooperatively (Gladden and Meyer 2007). The functional readout of Xchromosome dosage is therefore equivalent to the dosage of X-linked factors expressed from XSEs that act to repress expression of xol-1. Thus far, only one autosomal signal element (ASE) has been identified as contributing to the denominator portion of the X:A ratio (Powell et al. 2005). The identified gene, sea-1, encodes a T-box transcription factor, which activates transcription of xol-1.
Autosomal dosage (ASE dosage) therefore counterbalances X dosage (XSE dosage) effects through antagonistic action on the master regulator switch, xol-1 (Fig. 2). The working hypothesis for how this plays out in both sexes is as follows. Diploid XX embryos produce a double dose of XSE repressors of $x o l-1$, which override the activating influence of ASEs. This keeps XOL-1 levels low and leads to hermaphrodite development and implementation of dosage compensation. Conversely, XO embryos produce a single dose of XSE repressors, which is insufficient to counteract the activating influence of ASEs. High XOL-1 levels lead to male development and failure to implement dosage compensation. In this way, the XSEs and ASEs translate an X:A ratio of either 0.5 or 1 into a switch for sex determination, and for deciding whether or not to implement dosage compensation.

\section{THE DOSAGE COMPENSATION COMPLEX (DCC) RESEMBLES THE CONDENSIN COMPLEX}

Understanding the assembly and composition of the DCC on the $\mathrm{X}$ chromosomes requires a brief introduction to the first few genes in the pathway that regulates both sex determination and dosage compensation (Fig. 2) (reviewed in 


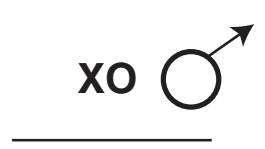

Soma : Dosage compensation OFF

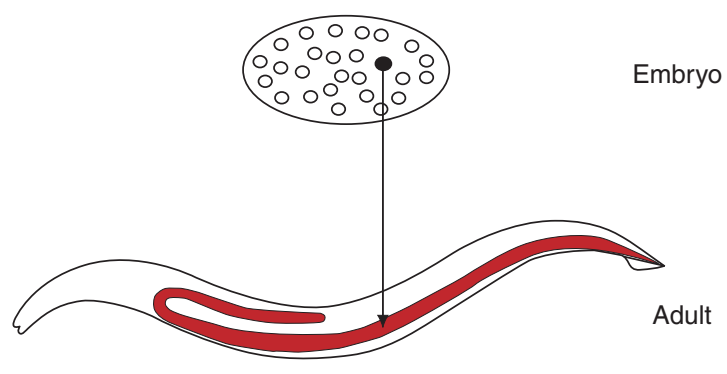

Germline : X repressed

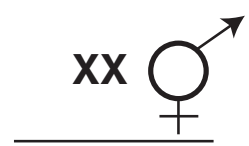

Soma : Dosage compensation ON 2 Xs down-regulated

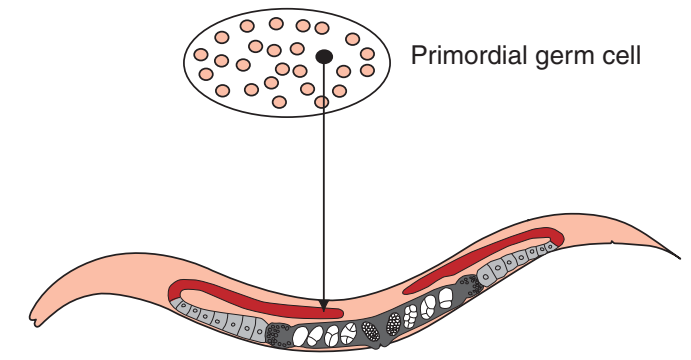

Germline : 2 Xs repressed
Somatic nuclei in XO: no down-regulation of the single $\mathrm{X}$ chromosome
Germline nuclei: global repression of $\mathrm{X}$ chromosomes
Somatic nuclei in XX: $50 \%$ down-regulation of both $\mathrm{X}$ chromosomes

Partial reactivation of $\mathrm{X}$ chromosomes in oogenesis

Figure 3. Overview of X-chromosome regulation. Dosage compensation occurs in somatic tissues only in XX hermaphrodites. Repression of the Xs in the germline occurs in both XO males and XX hermaphrodites. Hermaphrodites display late and partial activation of X-linked genes during late pachytene of oogenesis. The black cell highlights the single primordial germ cell in the embryo that generates the germline in the adult gonad.

Meyer 1997). xol-1 (xol for XO-lethal), the first gene in the pathway, is considered a master switch gene because its activity is determined by the X:A ratio and it, in turn, dictates whether the pathway leads to male or hermaphrodite development. XOL-1 is a negative regulator of $s d c-2$ ( $s d c$ for sex determination and dosage compensation defective) gene. The $s d c$ genes, $s d c-1, s d c-2$, and $s d c-3$, encode components of the DCC and also regulate the her-1 (her for hermaphroditization of XO animals) sex determination gene. In XO embryos, an X:A ratio of 0.5 leads to high XOL- 1 protein levels and low SDC-2 protein levels; the DCC is not assembled, dosage compensation is not implemented, and the sex determination gene her-1 is expressed, leading to male sexual development. In XX embryos, an X:A ratio of 1 results in low XOL-1 and high SDC-2 levels; the DCC is assembled, dosage compensation is implemented, and her-1 is repressed, leading to hermaphrodite sexual development.

In addition to the SDC proteins (SDC-1, SDC-2, and SDC-3), the DCC also contains a set of DPY (DPY for dumpy) proteins (DPY-21, DPY-26, DPY-27, DPY-28, and DPY-30), MIX-1 (MIX for mitosis and X-associated), and the more recently identified CAPG-1 protein (Csan- kovszki et al. 2009) (see Table 1; reviewed in Meyer 2005). Significant insights into the mechanism of dosage compensation in worms came from the discovery that a portion of the C. elegans DCC resembles the $13 S$ condensin I complex (Table 1 and Fig. 4). The condensin complex is conserved among all eukaryotes and is essential for proper chromosome compaction and segregation during mitosis and meiosis (reviewed in Hirano 2002). The core of the DCC includes DPY-26, DPY-27, DPY-28, MIX-1, and CAPG-1, which are homologous to members of the condensin complex. In fact, in addition to their functions in the DCC, all of the core proteins except DPY-27 function in a true condensin complex with SMC-4 to form the canonical five-subunit condensin I that acts in mitosis and meiosis. The SDC proteins DPY-21 and DPY-30, however, do not resemble known condensin subunits. The current view is that the DCC complex was derived from an ancestral condensin complex for targeted down-regulation of genes on the $\mathrm{X}$ chromosome, likely through a mechanism involving some degree of chromatin condensation.

Why is the DCC assembled only in XX embryos? Surprisingly, most of the DCC components are maternally 
S. Strome et al.

Table 1. Components that regulate gene expression from the $X$ chromosome

\begin{tabular}{|c|c|c|}
\hline Protein & Complex & $\begin{array}{l}\text { Homolog and/or conserved } \\
\text { domains }\end{array}$ \\
\hline SDC-1 & DCC & $\mathrm{C} 2 \mathrm{H} 2$ zinc-finger domain \\
\hline SDC-2 & DCC & Novel protein \\
\hline SDC-3 & DCC & $\begin{array}{l}\text { C2H2 zinc-finger domain and } \\
\text { myosin-like ATP-binding } \\
\text { domain }\end{array}$ \\
\hline DPY-21 & DCC & $\begin{array}{l}\text { Conserved protein; no recognizable } \\
\text { motifs }\end{array}$ \\
\hline DPY-27 & DCC & $\begin{array}{l}\text { Condensin subunit homolog } \\
\text { SMC-4/XCAP-C }\end{array}$ \\
\hline DPY-30 & DCC & $\begin{array}{l}\text { Subunit of the MLL/COMPASS } \\
\text { complex }\end{array}$ \\
\hline DPY-26 & DCC, condensin I & Condensin subunit XCAP-H \\
\hline DPY-28 & DCC, condensin I & $\begin{array}{l}\text { Condensin subunit XCAP-D2/ } \\
\text { Cnd1/Ycs4p }\end{array}$ \\
\hline CAPG-1 & DCC, condensin I & Condensin subunit XCAP-G \\
\hline MIX-1 & DCC, condensin I, II & $\begin{array}{l}\text { Condensin subunit SMC-2/ } \\
\text { XCAP-E }\end{array}$ \\
\hline MES-2 & MES- $2 / 3 / 6$ & $\begin{array}{l}\text { PRC2 subunit } \mathrm{E}(\mathrm{Z}) / \mathrm{EZH} 2 \text {; SET } \\
\text { domain }\end{array}$ \\
\hline MES-3 & MES-2/3/6 & Novel protein \\
\hline MES-6 & MES- $2 / 3 / 6$ & $\begin{array}{l}\text { PRC2 subunit ESC/EED; WD40 } \\
\text { domains }\end{array}$ \\
\hline MES-4 & Unknown & $\begin{array}{l}\text { NSD proteins; PHD fingers and } \\
\text { SET domain }\end{array}$ \\
\hline
\end{tabular}

supplied via the oocyte to both $\mathrm{XX}$ and $\mathrm{XO}$ embryos. The key regulator of DCC assembly is SDC-2 (Dawes et al. 1999). SDC-2 is not maternally supplied and is produced only in XX embryos (Fig. 2), in which it, along with SDC-3 and DPY-30, recruits the remaining DCC complex subunits to the $\mathrm{X}$ chromosomes (Fig. 5). In fact, driving expression of SDC-2 in XO embryos is sufficient to cause assembly of the DCC on the single $\mathrm{X}$ chromosome and to trigger dosage compensation, which kills the XO embryos. SDC-2 thus directs the specific recruitment of other DCC components, most of which have other cellular roles, and co-opts their activities for dosage compensation and sex determination.

\section{RECRUITMENT AND SPREADING OF THE DCC}

Several studies have focused on identifying features of the $\mathrm{X}$ chromosome involved in recruiting the DCC. An elegant approach was used to investigate whether the DCC is recruited independently to many sites or just a few sites, after which complexes spread into adjoining chromosomal regions (Lieb et al. 2000; Csankovszki et al. 2004; Meyer 2005). Worm strains containing duplications of different regions of the X chromosome were stained for DCC components. Association of the DCC with a duplication was interpreted to mean that the duplicated region contained a DCC re- cruitment site. Lack of DCC association with the duplication, but association of DCC with the corresponding region of the intact $X$, was interpreted to mean that the duplicated $\mathrm{X}$ region lacks a DCC recruitment site and instead acquires DCC at its endogenous locus by spreading from adjoining regions. These experiments identified at least 13 regions that can independently recruit the DCC, and provided evidence for DCC spreading along the X (Fig. 5A) (Csankovszki et al. 2004). Some regions recruit strongly and others weakly, suggesting either the presence of varying numbers of recruitment sites or of sites with varying capacity to recruit and/or promote spreading along the X (Csankovszki et al. 2004).

Finer mapping of the $\mathrm{X}$-chromosome regions that are capable of recruiting the DCC identified smaller regions, called rex sites (rex for recruitment elements on the $\mathrm{X}$ ) (McDonel et al. 2006). To test whether rex recruitment sites have a common DNA sequence, it was necessary to identify many other sites of DCC recruitment to the X. The key technology for these experiments was chromatin immunoprecipitation (ChIP) using two DCC subunits (DPY-27 and SDC-3) coupled to microarray analysis (ChIP-chip). This provided maps of DCC binding sites across the X and resulted in the identification of a 10-bp DNA sequence motif enriched at sites of high DCC binding (Ercan et al. 2007). The 10-bp motif was extended to 12 bp by a combination of ChIP-chip and extrachromosomal recruitment assays (Jans et al. 2009). The 12-bp DNA sequence motif (Fig. 5B) is necessary for recruiting the DCC to rex sites. It is estimated that there are 100-300 rex sites distributed along the $\sim 17$ MB X chromosome (Jans et al. 2009). Although enriched on the $\mathrm{X}$ and more clustered on the X (Ercan et al. 2007), many copies of the 12-bp DNA sequence motif are present on the autosomes, but do not recruit the DCC. Thus, the motif is important, but not sufficient for DCC recruitment. The DNA or chromatin context of the motif may contribute to DCC recruitment, and clustering may be important for increasing the affinity for recruitment. SDC2 is the first protein to localize to the $\mathrm{X}$, and it recruits the other DCC members to the X chromosome, but whether it is SDC-2 or another factor that directly recognizes the DNA sequence motif at rex sites is not known. Regardless, it is clear that the initial recruitment of the DCC to the X in XX hermaphrodite embryos has at least two components: the DNA sequence motif at rex sites and the SDC-2 protein. It is interesting to note that in mammals and fruit flies, the dosage compensation machinery is targeted to the $\mathrm{X}$ chromosome by a combination of $\mathrm{X}$-specific noncoding RNAs and X-chromosome sequence elements (see Brockdorff and Turner 2014; Kuroda and Lucchesi 2014). There is no evidence to date, however, that noncoding RNAs function in C. elegans dosage compensation. 
Vertebrates

Condensin I (13S)

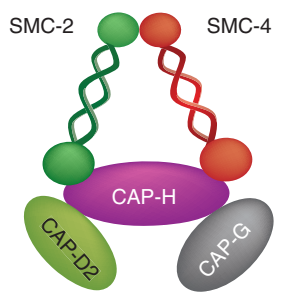

Resolves and condenses mitotic and meiotic chromosomes

\section{C. elegans}

Condensin I

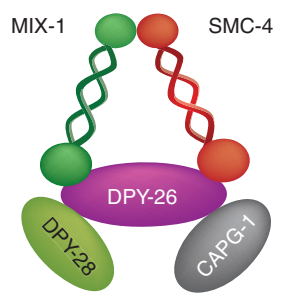

Resolves and condenses mitotic and meiotic chromosomes
Condensin II

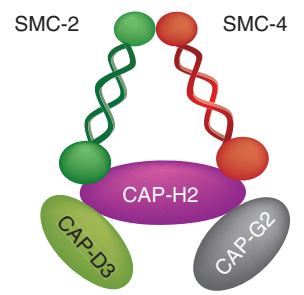

Resolves and condenses mitotic and meiotic chromosomes

\begin{tabular}{ll} 
Subunits & \multicolumn{1}{c}{ Vertebrates } \\
\hline Core subunits (common to I \& II) \\
ATPase & CAP-E/SMC2 \\
ATPase & CAP-C/SMC4 \\
I-specific subunits & \\
HEAT & CAP-D2 \\
HEAT & CAP-G \\
Kleisin & CAP-H \\
II-specific subunits & \\
HEAT & CAP-D3 \\
HEAT & CAP-G2 \\
Kleisin & CAP-H2/nessy \\
\hline
\end{tabular}

Condensin IDC

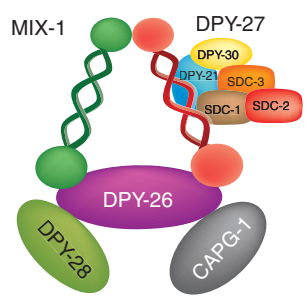

Reduces X-linked gene expression

Figure 4. The DCC and condensin complexes. The worm DCC resembles the condensin complex, which functions in condensing chromosomes during nuclear division. In particular, the DCC contains several subunits that are homologous to the XCAP (XCAP for Xenopus chromosome-associated polypeptide) subunits of the $13 \mathrm{~S}$ condensin complex I, originally characterized in Xenopus. There are two condensin complexes in most metazoans and three complexes in C. elegans. MIX-1 is present in all three C. elegans condensin complexes. Three additional DCC subunits (DPY-26, DPY-28, and CAPG-1) are present in both condensin I and condensin $\mathrm{I}^{\mathrm{DC}}$. The SDC proteins, DPY-21 and DPY-30, do not resemble known condensin subunits; they instead function in localizing condensin $\mathrm{I}^{\mathrm{DC}}$ to the X chromosome. (Adapted from Meyer 2005 and Csankovszki et al. 2009.)

A critical unanswered question is how DCC spreading occurs from the initial recruitment sites (Fig. 5B). Most of the tested sites on the $\mathrm{X}$ chromosome are not able to recruit the DCC by themselves, yet the DCC is bound to them in the context of the natural chromosome. The DCC accumulates through a spreading mechanism, especially at the promoters of actively transcribed genes (Ercan et al. 2007). In experiments using X-to-autosome end-to-end fusion chromosomes, the DCC was also shown to spread from the $\mathrm{X}$ to juxtaposed autosomal sequences, indicating that unlike recruitment, DCC spreading is not dependent on any particular property of X-linked DNA sequences (Ercan et al. 2009). Furthermore, DCC spreading onto juxtaposed autosomal DNA is concentrated on the promoter regions of actively transcribed genes, just as it is on the natural X chromosome.

In summary, spreading of the DCC onto active promoters is governed by a mechanism that is not specific to the $\mathrm{X}$ chromosome, but DCC spreading is largely restricted to the
$\mathrm{X}$ via recruitment of the DCC to rex sites (Fig. 5). What property of active promoters does the DCC recognize? One candidate is a histone variant H2A.Z because upon depletion of H2A.Z, DCC immunostaining is no longer as sharply restricted to the $\mathrm{X}$ chromosome as in wild type (Petty et al. 2009). Spreading may also be mediated by cooperative interactions between DCC complexes, physical interaction with the transcription machinery, or local modification of chromatin into a structure that facilitates more DCC binding in a self-reinforcing loop as shown for the spread of heterochromatin in Schizosaccharomyces pombe (see Martienssen and Moazed 2014).

\section{EFFECTS OF THE DCC: DOWN-REGULATION OF X-LINKED GENES AND THE AUTOSOMAL GENE her-1}

Mammals, fruit flies, and worms appear to have co-opted different preexisting chromatin complexes to serve the spe- 
S. Strome et al.

A

$\mathrm{X}$ chromosome
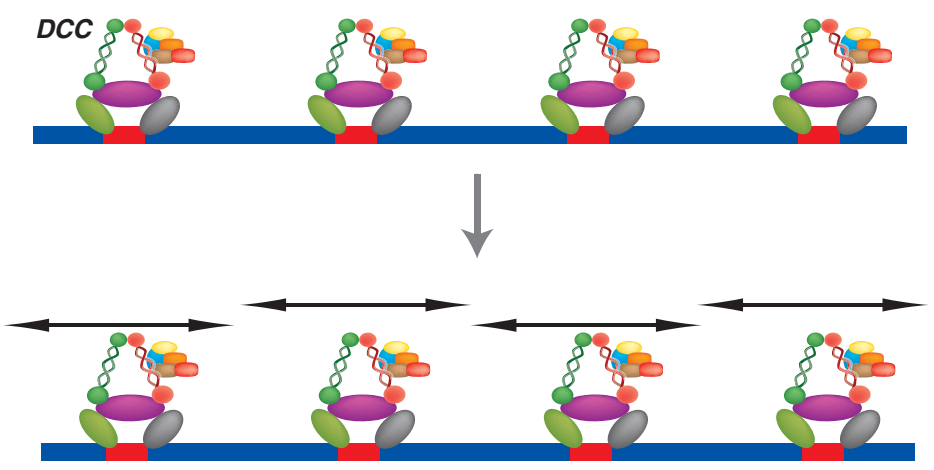

$\downarrow$

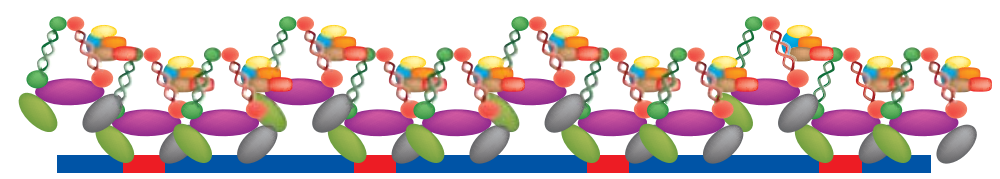

her-1 locus
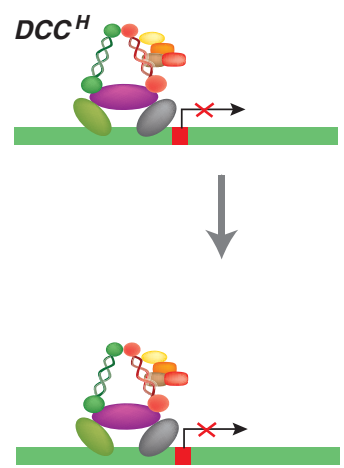

$\downarrow$

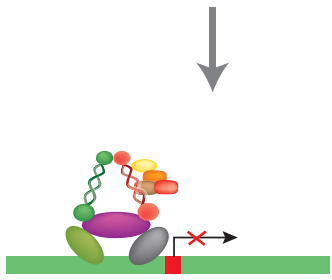

B

3. Short-range spreading, perhaps transcription-coupled

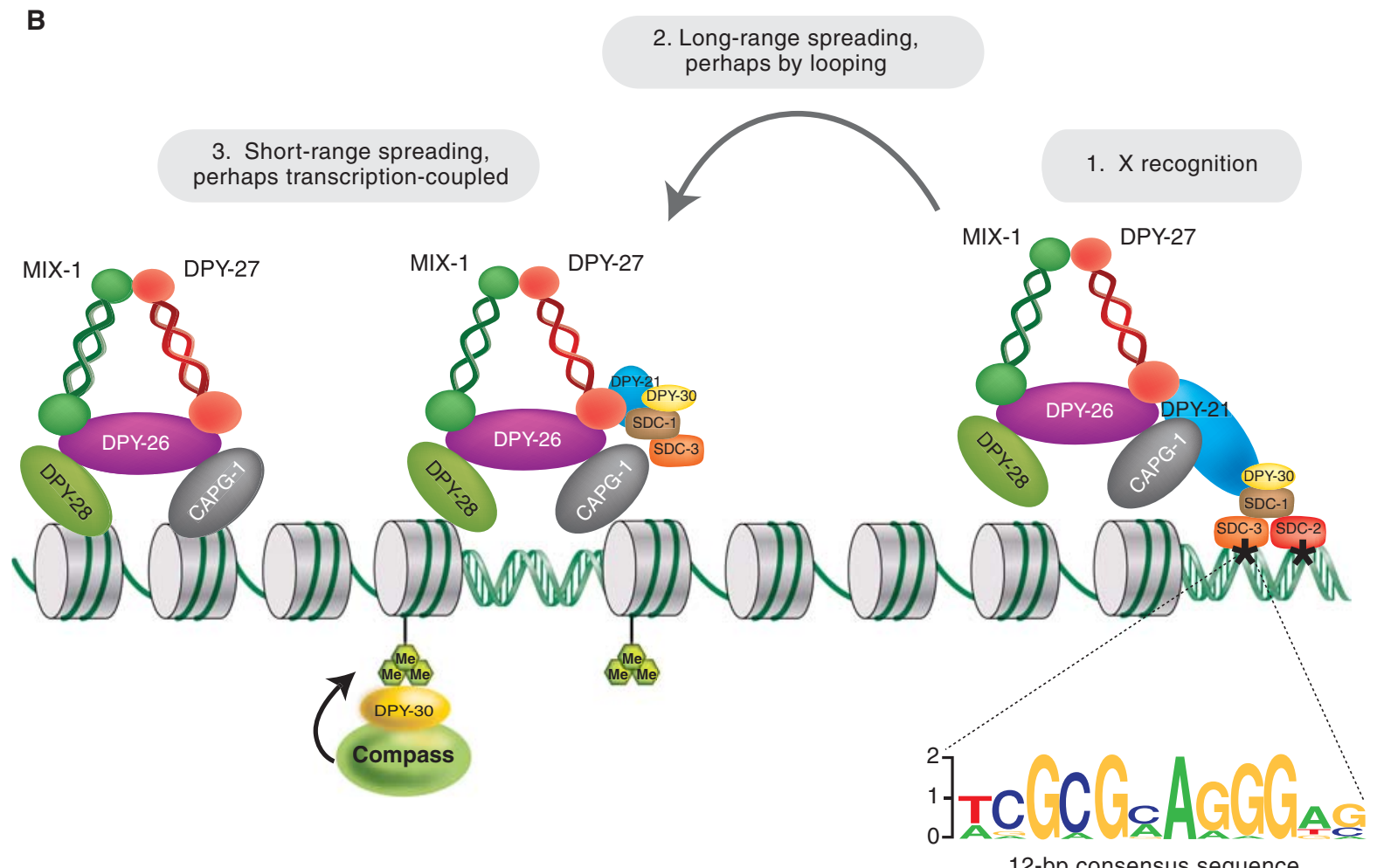

2. Long-range spreading, perhaps by looping

Figure 5. DCC recruitment and spreading on the X chromosome. (A) The DCC is recruited to approximately 100 to 300 recruitment elements and spreads along both $\mathrm{X}$ chromosomes. It also binds to the upstream region of the autosomal gene her-1 and reduces expression by 20 -fold, denoted $\mathrm{DCC}^{\mathrm{H}}$ to indicate that the complex that binds to her-1 lacks the DPY-21 protein. (Adapted from Alekseyenko and Kuroda 2004.) (B) From initial recruitment sites, the DCC spreads and accumulates preferentially at promoters by an unknown mechanism. The recruitment sites on the $\mathrm{X}$ chromosome, indicated by asterisks, contain multiple 12-bp DNA sequence motifs (shown below the DNA) that are important for recruitment. DCC binding is dynamic during development and is tuned to the transcriptional activity of individual genes. DCC accumulation is high in the body of highly expressed genes. (Adapted from Ercan and Lieb 2009.) 
cialized role of modulating gene expression from the $\mathrm{X}$ chromosome. Mammals have used heterochromatin-based silencing to inactivate one of the two Xs in the XX sex. Fruit flies have used chromatin-modifying machinery to alter the state of the single $\mathrm{X}$ in XYanimals, leading to up-regulation of gene expression. C. elegans has adapted a chromosome condensation mechanism typically used for mitosis and meiosis to down-regulate both Xs in the XX sex. Regulating chromatin structure to achieve modest twofold effects on Xlinked gene expression, as occurs in worms and fruit flies, seems mechanistically challenging. The precise mechanism of down-regulation in worms and how down-regulation is limited to approximately twofold are critical questions.

Microarray analysis of RNA levels in XX wild type, XX DCC mutants, and XO embryos that are phenotypically hermaphrodite provided insight into C. elegans X-chromosome dosage compensation (Jans et al. 2009). In XX DCC mutant embryos, $\sim 40 \%$ of expressed X-linked genes showed an increase in transcript levels, whereas only $2.5 \%$ showed a decrease. This is consistent with the expectation that the DCC represses the X chromosome. However, there was not a uniform twofold effect. The range of change was from 1.5-fold (the lowest ratio allowed for a "significant change") to 10-fold. Nevertheless, the average effect across $\mathrm{X}$-linked genes whose expression significantly increased in DCC mutants was approximately twofold.

The mechanism by which the DCC achieves an average twofold reduction in transcript levels remains unknown. Microarray experiments revealed a disconnect between DCC binding and transcriptional response upon loss of DCC function. At the gene level, genes that were bound by the DCC were equally likely to be dosage compensated or not. This was interpreted to mean that the DCC does not directly regulate the genes to which it binds, but rather that it regulates "at a distance" (Fig. 6A) (Jans et al. 2009). At the genome level, although the DCC binds primarily to the X chromosome, loss of DCC function causes misexpression of some autosomal genes: repression of $\sim 25 \%$ and activation of $7 \%$. Jans et al. hypothesized that the DCC may repel a rate-limiting general transcription factor from the $\mathrm{X}$, and that in the absence of the DCC this factor would be re-distributed on all chromosomes (Fig. 6B) (Jans et al.

A

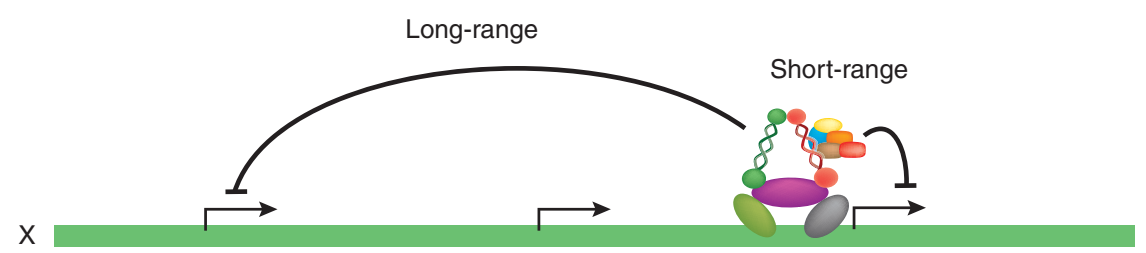

B

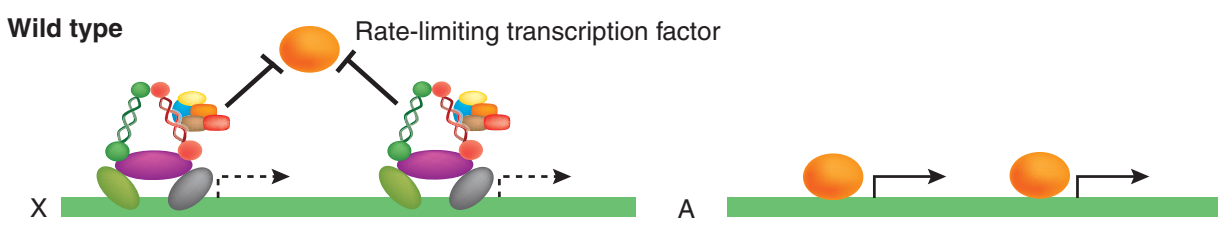

DCC mutant

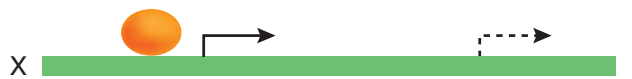

A

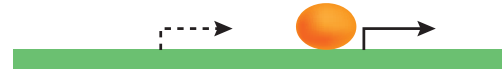

Figure 6. Models for how DCC concentrated on the X chromosomes may regulate gene expression. Upon loss of DCC function, most of the gene expression changes on the $\mathrm{X}$ chromosome are an increase in transcription, consistent with the DCC repressing X-chromosome transcription. However, only about half of DCC-bound genes increase in expression and many genes whose expression increases are not bound by the DCC. $(A)$ The DCC may repress genes locally or cause structural changes that affect distant loci. $(B)$ On the autosomes, the majority of expression changes due to loss of DCC function are a decrease in transcription. This could be explained by a model in which the DCC repels an activator from the X chromosomes. In the absence of the DCC, the activator is more evenly distributed between the $\mathrm{X}$ chromosomes and autosomes, resulting in increased gene expression from the $\mathrm{X}$ and decreased gene expression from the autosomes. An alternative model (not shown) is that the DCC may repress genes locally, and in the absence of the DCC additional effects on the X and autosomes result from the increase in transcription of hundreds of genes encoded from the X. The possibilities discussed above are not mutually exclusive. 
2009). An alternative interpretation to explain the disconnect between binding and regulation at both the gene level and genome-wide level is that the DCC does indeed regulate genes directly at its sites of binding, but that steady-state measurements of mRNA levels in XX DCC mutants are dominated by secondary effects, rather than direct transcriptional responses to dosage compensation defects. Even in yeast, in which transcription factors bind very near to the genes they regulate, overlap between genes bound by a transcription factor and genes misregulated in the absence of that factor is often small (Gao et al. 2004; Chua et al. 2006; Hu et al. 2007). The issue of whether the DCC acts locally and/or at a distance is therefore unresolved. A high priority should be to determine whether the mechanism of DCC action is local, affecting genes near where it is bound, or whether the mechanism acts at a distance to affect genes across the entire $\mathrm{X}$.

Histone modifications are often involved in establishing more "active" or "repressed" chromatin regions. In fruit flies, up-regulation of $\mathrm{X}$ gene expression in males is associated with H4K16 acetylation (H4K16ac) and loss of linker histone from the X (see Kuroda and Lucchesi 2014). $\mathrm{H} 4 \mathrm{~K} 16 \mathrm{ac}$ is enriched on the $\mathrm{X}$ chromosome by the action of MOF acetyltransferase, a subunit of the fly DCC, reducing compaction of nucleosomes. Its effect on transcription has been shown to be on transcription initiation (Conrad et al. 2012) and elongation (Larschan et al. 2011). To date, no histone modification activity has been attributed to the C. elegans DCC. DPY-30, a component of the DCC, is a noncatalytic structural component of the H3K4 methylating MLL/COMPASS complex (Fig. 5B) (Pferdehirt et al. 2011), but whether DPY-30 regulates H3K4 methylation specifically on the X chromosome has not been tested.

Although the DCC has no known direct histone-modifying activity, there is a newly recognized involvement of the histone modification monomethylated H4K20 (H4K20me1) in dosage compensation. H4K20me1, which is associated with gene repression in other species (Karachentsev et al. 2005; Yang and Mizzen 2009), becomes enriched on the $\mathrm{X}$ chromosomes in XX hermaphrodites (Liu et al. 2011). H4K20mel enrichment is dependent on functional DCC, and accumulation of H4K20mel occurs after dosage compensation is established (Vielle et al. 2012). Immunofluorescence analysis of H4K20me1 and H4K16ac in wild-type adult somatic nuclei showed that the X chromosomes have higher levels of H4K20mel and lower levels of H4K16ac compared to the autosomes (Wells et al. 2012). Reducing SET-1 enzyme, which monomethylates H4K20, resulted in increased levels of H4K16ac on the Xs. Reducing the SIR-2.1 enzyme, which is responsible for depletion of H4K16ac on the X, however, did not affect H4K20me1 enrichment on the Xs (Wells et al. 2012). Therefore, it appears that enrichment of H4K20me1 on the X chromosomes results in a reduction of $\mathrm{H} 4 \mathrm{~K} 16 \mathrm{ac}$ levels on the $\mathrm{X}$ (Vielle et al. 2012; Wells et al. 2012). It is not clear whether H4K20me1 exerts all of its effect on transcription through H4K16ac. In C. elegans as well as other organisms, H4K20me1 is greatly increased on chromosomes during mitosis, and human condensin II binding to chromosomes is mediated in part by H4K20me1 (Liu et al. 2010). It is possible that enrichment of H4K20me1 on the C. elegans X chromosomes has a mechanistic connection to condensed chromosome structure.

The DCC may function to restrict access of RNA polymerase or transcription factors to promoter regions, impede progression of RNA polymerase through transcription units, or slow reinitiation of transcription at each gene. These possibilities are consistent with the finding that loss of DCC function leads to increased RNA polymerase II on the $\mathrm{X}$ chromosome (Pferdehirt et al. 2011). Given the similarity of the DCC to the $13 \mathrm{~S}$ condensin I complex, a likely mechanism for the down-regulation of gene expression is DCC-mediated condensation of chromatin. It is not known, however, whether the $\mathrm{X}$ chromosome is more condensed compared to the autosomes. X-chromosome promoters have higher nucleosome occupancy than autosomal promoters, but this higher nucleosome occupancy is not dependent on the DCC and is likely due to the higher GC content of X-linked promoters (Ercan et al. 2011). Future studies are required to dissect the functional connection between the DCC, H4K20 methylation, X-chromosome compaction, nucleosome organization, and transcription.

Clues about the mechanism of repression may also be found at her-1, the only autosomal target at which the DCC is known to function, and which displays 20-fold DCCmediated down-regulation of gene expression (Fig. 5A) (Dawes et al. 1999; Chu et al. 2002). Repression of her-1 promotes hermaphrodite sexual development (Fig. 2). An interesting question is how the DCC achieves 10 -fold greater repression at her-1 than it achieves on the $\mathrm{X}$ chromosome. A few differences between X-chromosome-associated DCC and her-1-associated DCC have been noted. First, although the DCC is recruited to the X chromosomes by SDC-2, the DCC is recruited to her-1 by SDC-3 (Dawes et al. 1999; Yonker et al. 2003). Second, a different sequence motif is responsible for recruitment of the DCC to her-1 than to the Xs (Chu et al. 2002). Third, DPY-21 is present on the X chromosomes, but not at the her-1 locus (Yonker and Meyer 2003). DPY-21 is a conserved protein with a proline-rich amino terminus, but comparisons to other proteins do not reveal an apparent function. It could be that DPY-21 modulates the function of the DCC to weakly repress transcription of many genes on the X, whereas the DCC without DPY-21 strongly represses transcription at the her-1 locus. 
Dissecting how the DCC at her-1 functions differently from the DCC localized to X may reveal important aspects of DCC mechanism.

\section{COMPENSATORY UP-REGULATION OF X-LINKED GENES}

Somatic down-regulation of the $\mathrm{X}$ chromosomes by the DCC compensates for the X-chromosome dosage difference between males and females. A second dosage compensation mechanism is thought to equalize overall transcript levels between $\mathrm{X}$ and autosomes. In animals with $\mathrm{X}$ chromosomes, cells in males contain a single $\mathrm{X}$ chromosome compared to two copies of each autosome (i.e., $\mathrm{XY}$ or $\mathrm{XO}, \mathrm{AA}$ ). This causes a potential haploinsufficiency for X-linked genes in males that is independent of the $\mathrm{X}$-chromosome dosage imbalance between sexes. Susumu Ohno first hypothesized that during the evolution of $\mathrm{X}$ chromosomes, transcription of X-linked genes was doubled from the single $\mathrm{X}$ to match the transcript output from a diploid complement of autosomes; dosage compensation in females evolved to repress the inappropriate increase in X transcription in XX animals (Ohno 1967). This combination of up- and down-regulation effectively creates a diploid dose of X transcripts in both sexes (Fig. 7). Although one study claimed that compensatory up-regulation of $\mathrm{X}$-linked genes does not occur in C. elegans (Xiong et al. 2010), subsequent studies that took into account the proliferation of germ cells during development showed that $\mathrm{X}$ up-regulation does occur in somatic cells (Deng et al. 2011;

\begin{tabular}{|c|c|c|c|c|}
\hline \multicolumn{3}{|c|}{$\begin{array}{c}\text { Female or } \\
\text { hermaphrodite }\end{array}$} & \multicolumn{2}{|c|}{ Male } \\
\hline Human & $\uparrow \mathrm{xx}$ & AA & $\uparrow X Y$ & AA \\
\hline Fly & $x X$ & AA & $\uparrow X_{Y}$ & AA \\
\hline Worm & $\uparrow x x$ & AA & $\uparrow \mathrm{x}$ & AA \\
\hline ve dose & $x x$ & AA & $x x$ & AA \\
\hline
\end{tabular}

Figure 7. Coordinated up-regulation and DCC-mediated down-regulation of X-linked gene expression. Dosage compensation between the sexes is accomplished differently in the three well-studied systems shown. In mammals, one of the $\mathrm{X}$ chromosomes in females is inactivated $($ small $\mathrm{x})$. In fruit flies, transcription from the single $\mathrm{X}$ in males is increased by a factor of 2 (larger X). In worms, transcription from both of the X chromosomes in hermaphrodites is decreased by a factor of 2 (smaller Xs). In all three systems, transcript levels from the $\mathrm{X}$ chromosome(s) and autosomes are similar in both females/hermaphrodites and males, suggesting that there is a mechanism to increase $\mathrm{X}$ transcription approximately twofold in both sexes (red arrows).
Kharchenko et al. 2011b). The clearest demonstration of this phenomenon was a microarray experiment showing that the mean and median $\mathrm{X}: \mathrm{A}$ expression ratio in $\mathrm{XO}$ animals was 0.98 , very close to the ratio of $\sim 1$ that occurs in $\mathrm{XX}$ animals, indicating that $\mathrm{X}$-linked genes are up-regulated in XO animals (Deng et al. 2011). Thus, up-regulation of $\mathrm{X}$-linked genes in both sexes requires a compensating mechanism that specifically down-regulates X-linked genes in animals with two X chromosomes. The molecular mechanism by which transcriptional up-regulation occurs on the $\mathrm{X}$ and how it is restricted to the $\mathrm{X}$ in both sexes are not known and are important areas for future investigation.

\section{GERMLINE DEVELOPMENT AND GLOBAL REPRESSION OF THE X CHROMOSOMES}

In C. elegans, the somatic mode of X-chromosome regulation by the DCC is inoperative in germ cells. Early evidence for this was the observation that some DCC components are not expressed in germ cells (e.g., SDC-2, DPY-27) and other DCC components are expressed in germ cells but are localized to all chromosomes (e.g., MIX-1, DPY-26, and DPY28). MIX-1, DPY-26, and DPY-28 are, in fact, components of canonical condensin I in C. elegans (Fig. 4). In the germline, those DCC proteins are engaged in more general roles in mitotic and meiotic chromosome organization and segregation.

The absence of DCC members in the germline raises the question of whether any mode of dosage compensation occurs in this tissue. Recall that one function of dosage compensation is to achieve equivalent expression of X-linked genes between the sexes for viability and normal development. Current evidence suggests that in contrast to the twofold down-regulation of both $\mathrm{X}$ chromosomes in XX somatic cells, the $\mathrm{X}$ chromosomes are globally repressed during most stages of germline development in both XX and $\mathrm{XO}$ animals (Fig. 3). The specific mechanisms that regulate the $\mathrm{X}$ chromosomes in germ cells bear little resemblance in either form or function to the somatic mechanisms already described in this article.

The adult gonads of both sexes in C. elegans contain an orderly progression of germ cell stages. Germ cells proliferate in the distal region, enter meiosis in the middle region, and complete gametogenesis in the proximal region (Figs. 1 and 8) (reviewed in Schedl 1997). In XO males, this progression occurs in a single tubular testis that continuously produces sperm. In XX hermaphrodites, two tubular gonad arms initially produce sperm during a late larval stage and then switch to the production of oocytes in adulthood. Mature oocytes are pushed into the spermathecae and are fertilized by sperm residing there before further extrusion into the uterus. The production of some sperm for a limited 
S. Strome et al.

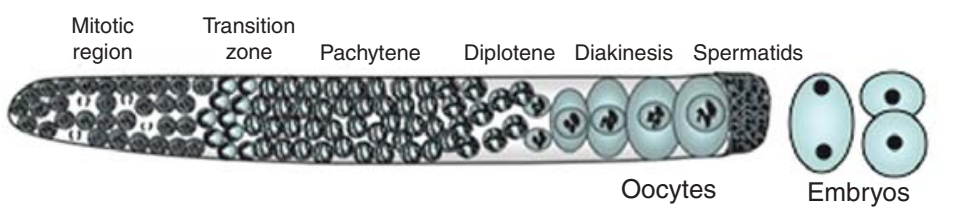

Chromatin marks on the Xs

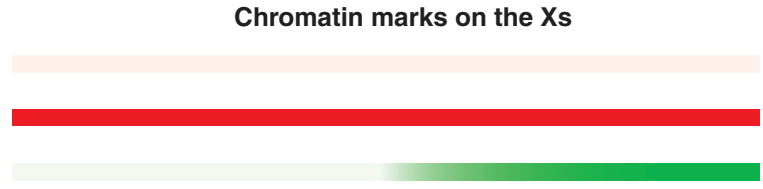

H3K9me2

H3K27me3

$\mathrm{H} 3 \mathrm{~K} 4 \mathrm{me} / 3$

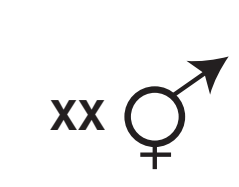

NO MSUC

MES repression
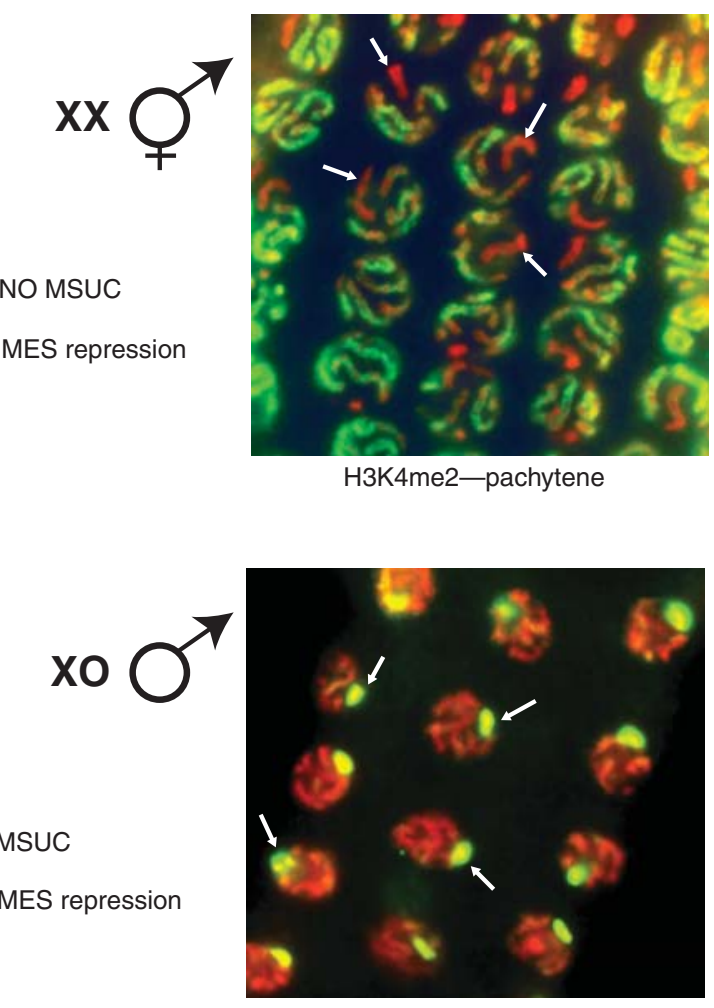

H3K9me2-pachytene

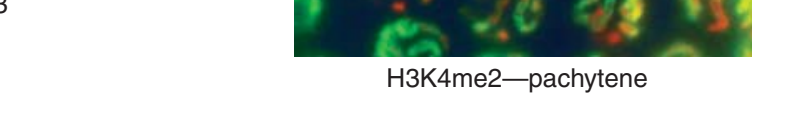

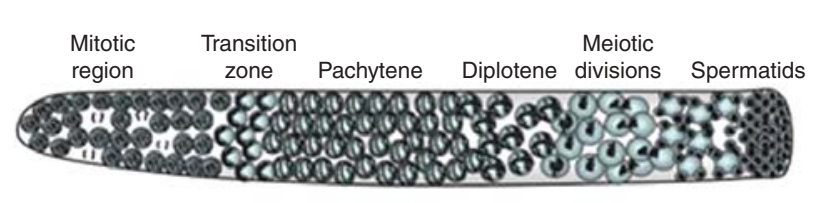

Chromatin marks on the $\mathrm{X}$

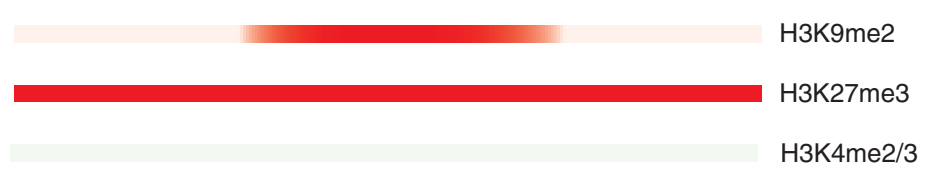

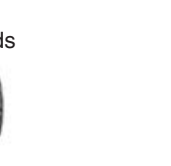

\begin{abstract}
Figure 8. Epigenetic regulation of the X chromosomes during germ cell development. In both sexes, germ cells progress through mitosis (left), enter meiosis in the transition zone, and progress through meiosis I prophase. Cells destined to form sperm in both sexes complete the meiotic divisions in the gonad. In hermaphrodites, cells destined to form oocytes progress through meiotic prophase in the gonad and complete the meiotic divisions after ovulation and fertilization. The presence of various histone modifications on the X chromosome(s) in germ cells is shown by red bars (for repressive modifications) and green bars (for activating modifications). As shown on the right, antibodies to particular histone modifications reveal that the X chromosomes in germ nuclei are marked differently than the autosomes and are repressed. H3K4me2 (green), a mark of actively expressed chromatin, is excluded from the Xs in XX pachytene nuclei. H3K9me2 (green), a mark of heterochromatin, is concentrated on the X in XO pachytene nuclei as part of MSUC (meiotic silencing of unsynapsed chromatin). DNA is stained red. Arrows indicate representative $\mathrm{X}$ chromosomes in each image.
\end{abstract}

time in development by XX worms thus allows the "hermaphroditic" mode of reproduction in the adult. However, the ovary and certain other somatic tissues in adult XX animals can be considered female in identity and function.

The X chromosomes in the germline are initially transcriptionally repressed both in XX hermaphrodites and in $\mathrm{XO}$ males. The evidence for $\mathrm{X}$ repression comes from immunofluorescence analysis and genome-wide transcript profiling. Immunostaining of germlines revealed that the $\mathrm{X}$ chromosomes have higher levels of repressive histone modifications (H3K27 methylation and H3K9 methylation) than the autosomes (Fig. 8) (Kelly et al. 2002; Bender et al. 2004). The $X$ chromosomes also lack several marks of actively expressed chromatin: H4 acetylation on K8, K12, and $\mathrm{K} 16, \mathrm{H} 3 \mathrm{~K} 4$ methylation, and the $\mathrm{H} 3$ variant $\mathrm{H} 3.3$ (Kelly et al. 2002; Ooi et al. 2006; Arico et al. 2011). Marks of active chromatin are absent from the $\mathrm{X}$ chromosomes throughout all stages of germline development in XO males. In XX hermaphrodites, such marks are absent from the X chromosomes in proliferating and early meiotic germ cells, but appear on the Xs during oogenesis (Kelly et al. 2002). These findings suggested that the X chromosomes are transcriptionally silent during all stages of germ cell development except oogenesis.

Genome-wide transcript profiling performed in worms that contain or lack germ cells showed that there is a striking asymmetry in the location of genes with germline-enriched expression; genes expressed in both the male and hermaphroditic germline, including those with enriched expression during spermatogenesis, are severely underrepresented on the X chromosome (Reinke et al. 2000; Reinke et al. 2004). Genes with enriched expression in oogenic germlines are 
also underrepresented on the $\mathrm{X}$, but not to the same degree. Consequently, most of the genes that are required for the viability and function of germ cells are located on the autosomes. Most of the oogenesis-associated genes that reside on the $\mathrm{X}$ chromosome are expressed late in meiosis, which correlates with the accumulation of active histone modifications on the $\mathrm{X}$ chromosomes during oogenesis (Fig. 8). Thus, the bias against $\mathrm{X}$-linkage is most stringent for genes that are common to both sexes and that function in the early stages of germ cell maturation. Consistent with this, primordial germ cells isolated from embryos express fewer genes from their X chromosomes than somatic cells at the same developmental stage, similar to the bias observed in adults (Spencer et al. 2011). Thus, preferential expression of autosomal genes is a feature of germ cells at all stages.

Recent transcript profiling from dissected adult hermaphrodite germlines has refined these results and revealed that the $\mathrm{X}$ is not as "silent" as previously thought (Wang et al. 2009; Tabuchi et al. 2011; Gaydos et al. 2012). Interestingly, genes that are transcribed in both soma and germline are observed to have significantly lower transcript levels in the germline relative to somatic tissues (Wang et al. 2009). It has been speculated that the X-linked transcripts detected in dissected full-length germlines come from oogenic germ cells, in which the $\mathrm{X}$ chromosomes acquire marks of active chromatin, as discussed in the preceding paragraphs. However, two observations instead suggest that there is some transcription from the $\mathrm{X}$ in germ cells at all stages and argue against oogenic germ cells being the sole source of X transcripts. First, isolated primordial germ cells express some X-linked genes (Spencer et al. 2011). Second, adult germlines that were dissected to include proliferating and early meiotic germ cells, but not oogenic germ cells, transcribe $\sim 15 \%$ of the genes on the X (Tabuchi et al. 2011).

In summary, in the C. elegans germline there is chromosome-wide and significant dampening of transcription from the X. As a consequence, germline development relies predominantly on expression of genes located on the autosomes. The $\mathrm{X}$ chromosome does house its fair share of "housekeeping genes" that are expressed in all cells, but they are expressed at lower levels in germ cells than in somatic cells. The predominant reliance of C. elegans germ cells on autosomal genes raises the question of how germline-expressed genes became preferentially located on the autosomes. Interestingly, a number of gene duplications with $\mathrm{X} /$ autosome paralogs have been identified in which the autosomal copy is uniquely required for germ cell function and the $\mathrm{X}$-linked copy functions in somatic lineages (Maciejowski et al. 2005). Gene duplication followed by germline dependence on the autosomal copy offers a potential mechanism for exclusion of essential germline genes from the inhospitable environment of the $\mathrm{X}$ chromosome. Genes that are only required during late oogenesis (i.e., only required in late stage female germ cells) were likely not subject to the selective pressures that excluded early germline-required genes from the X chromosome. The selective pressures likely included the evolved absence of a pairing partner for the $\mathrm{X}$ in male meiosis, as discussed in Section 8. Similar forces appear to be acting in other species including fruit flies and mammals (Wu and $\mathrm{Xu} 2003$ ).

\section{MEIOTIC SILENCING OF THE SINGLE X IN MALES}

The earliest suggestion that the $\mathrm{X}$ chromosome differs from the autosomes in the germline came from cytological observations. The single $\mathrm{X}$ in male worms hypercondenses during pachytene in meiotic prophase, forming a ball-like structure reminiscent of the XY "sex body" seen during male meiosis in mammals (Fig. 8) (Goldstein and Slaton 1982; Handel 2004). The autosomes condense later in meiotic prophase near the onset of spermatogenesis. Premature $\mathrm{X}$ condensation is also seen during sperm meiosis in XX hermaphrodites and in sexually transformed XX males, suggesting that premature $\mathrm{X}$ condensation is in response to germ cell sex and not to X-chromosome ploidy or pairing status. Accordingly, in XX hermaphrodites, germ cells destined for oogenesis do not show premature $\mathrm{X}$ condensation.

In addition to premature condensation, a separate mechanism that depends on unpaired DNA in meiosis causes the single $\mathrm{X}$ chromosome in $\mathrm{XO}$ males to transiently accumulate a striking enrichment of $\mathrm{H} 3 \mathrm{~K} 9 \mathrm{me} 2$, which appears during pachytene and disappears by diakinesis (Kelly et al. 2002; Bessler et al. 2010) (Fig. 8). This X enrichment of $\mathrm{H} 3 \mathrm{~K} 9 \mathrm{me} 2$ does not occur during spermatogenesis in either XX hermaphrodites or sexually transformed XX males, but does occur during pachytene in sexually transformed XO hermaphrodites and in XX animals in which the X chromosomes do not pair (e.g., him-8 mutants; Bean et al. 2004; Bessler et al. 2010). The specific acquisition of a heterochromatin mark on the $\mathrm{X}$ in $\mathrm{XO}$ meiosis thus appears to be a consequence of its unpaired status, and not the sex of the germline through which it is passing. Targeting of H3K9me2 to unpaired DNA is not limited to X-chromosome sequences; it is also found on unpaired autosomal fragments and translocations (Bean et al. 2004). H3K9me2 on unpaired X chromosomes is generated by the SETDB1 homolog MET-2 and its pattern is regulated by the chromatin protein HIM-17 (Reddy and Villeneuve 2004; Bessler et al. 2010). The finding that met-2 mutant males do not display defects in transmission of $\mathrm{X}$ chromosomes during 
meiosis suggests that concentrating $\mathrm{H} 3 \mathrm{~K} 9 \mathrm{me} 2$ on the $\mathrm{X}$ is not essential for proper meiotic chromosome segregation. Whether loss of $\mathrm{H} 3 \mathrm{~K} 9 \mathrm{me} 2$ affects $\mathrm{X}$ silencing in males, however, has not yet been assessed.

Targeted repression of unpaired DNA in meiosis is not unique to C. elegans. Similar recognition and repression of unpaired DNA occurs in other organisms during meiosis, including Neurospora and mice. This is referred to as MSUC (meiotic silencing of unsynapsed chromatin; also referred to as MSUD, for meiotic silencing of unpaired DNA; Shiu et al. 2001; Baarends et al. 2005; Turner 2005; Kelly and Aramayo 2007). In mouse, for example, the poorly synapsed XY "sex body" is similarly enriched in H3K9me2 during male meiosis, and this is a consequence of its unsynapsed status (Cowell et al. 2002; Turner et al. 2005). Meiotic silencing in Neurospora requires the activity of proteins with conserved roles in RNA interference (see Aramayo and Selker 2013). These include an RNA-dependent RNA polymerase (RdRP), an Argonaute-related protein (a conserved component of RNA-induced silencing complexes), and the Dicer nuclease (reviewed in Kelly and Aramayo 2007; see Martienssen and Moazed 2014). In C. elegans, the enrichment of $\mathrm{H} 3 \mathrm{~K} 9 \mathrm{me} 2$ on unpaired DNA requires the RdRP EGO-1 and the Argonaute protein CSR-1, but does not require Dicer (Maine et al. 2005; She et al. 2009). This suggests that although there is conservation of meiotic silencing (repression of unpaired DNA), the mechanism by which this is achieved likely evolved differently in different organisms.

In contrast to what happens in $\mathrm{XO}$ male meiosis, the $\mathrm{X}$ chromosomes in either XX spermatogonia or XX oogonia are not enriched in $\mathrm{H} 3 \mathrm{~K} 9 \mathrm{me} 2$. This difference is likely because of the complete synapsis of the Xs in hermaphrodite meiosis. Why would silencing of unpaired DNA be a conserved feature of sexual reproduction? In many organisms, homolog pairing is unique to meiosis, and during synapsis novel insertions unique to one homolog would be exposed as regions of unpaired DNA. It has been proposed that recognition and silencing of unpaired sequences during meiosis provides a mechanism for self-scanning of a diploid genome, and could provide protection against invasion by, or expansion of, transposable elements. This protection would be needed only in the germline because somatic transposon insertions or expansions are not passed to the next generation. As a consequence, genes required during meiosis would encounter a strong selection against residence on an unpaired chromosome (such as the male X). Such selection may have led to the unique genetic profile of the $\mathrm{X}$ that is observed in C. elegans, as discussed in Section 7. It is interesting to speculate that the genomic warfare between transposons and their hosts, and the silencing mechanisms that have evolved as weapons in this battle, have shaped genomes and led to some of the X-autosome differences discussed in Section 7.

\section{REGULATION OF X-CHROMOSOME REPRESSION BY THE MES HISTONE MODIFIERS}

Section 8 describes repression via heterochromatin formation that is specific to the single $\mathrm{X}$ in $\mathrm{XO}$ males and restricted to the pachytene stage of meiosis due to MSUC. How are the $\mathrm{X}$ chromosomes maintained in a repressed chromatin state during other stages of male germline development and in the germlines of XX hermaphrodites? Genetic screens for maternal-effect sterile (mes) mutants identified a set of four mes genes that participate in X-chromosome repression in XX animals and likely in XO animals as well. A combination of genetic and molecular analyses have shown that the encoded MES proteins effect repression through regulating part of the spectrum of histone modifications found on the $\mathrm{X}$ chromosomes in germ cells. Their functions are essential for the survival and development of germ cells.

The MES proteins generate two opposing modifications on the tail of histone H3: methylation of H3K27, which is associated with gene repression, and methylation of H3K36, which is associated with active gene expression. Methylation of H3K27 is catalyzed by MES-2 in association with MES-3 and MES-6 (Fig. 9A). This trimeric complex resembles the Polycomb repressive complex PRC2 in fruit flies and vertebrates (Xu et al. 2001; Bender et al. 2004; Ketel et al. 2005; see Grossniklaus and Paro 2014). MES-2 and MES- 6 are the worm orthologs of two PRC2 subunits, $\mathrm{E}(\mathrm{Z})$ (enhancer of zeste) and ESC (extra sex combs; Table 1); MES-3 is a novel protein. MES-2's SET domain is responsible for its histone lysine methyltransferase (HKMT) activity, whereas MES-6 and MES-3 appear to be required either for substrate binding or to boost catalytic activity (Ketel et al. 2005).

MES-2, MES-3, and MES- 6 are responsible for all detectable $\mathrm{H} 3 \mathrm{~K} 27 \mathrm{me} 2$ and $\mathrm{H} 3 \mathrm{~K} 27 \mathrm{me} 3$ in the germline and in early embryos, but another as-yet undiscovered HKMT contributes to $\mathrm{H} 3 \mathrm{~K} 27$ methylation in the primordial germ cells and in larval and adult somatic tissues. Importantly, within the germline $\mathrm{H} 3 \mathrm{~K} 27 \mathrm{me} 3$ is enriched on the $\mathrm{X}$ chromosomes (Fig. 8) (Bender et al. 2004). Accordingly, one consequence of abolishing H3K27 methylation in the germline is activation of genes on the X. In progeny of mes-2, mes-3, or mes- 6 mutant mothers, the $\mathrm{X}$ chromosomes in the germline lack $\mathrm{H} 3 \mathrm{~K} 27 \mathrm{me} 2 / 3$, acquire marks of active chromatin (e.g., H3K4me and H4K12ac), and become decorated with the transcriptionally active form of RNA polymerase II (Fong et al. 2002; Bender et al. 2004). These findings suggest that the MES-2/3/6 complex participates, 
A
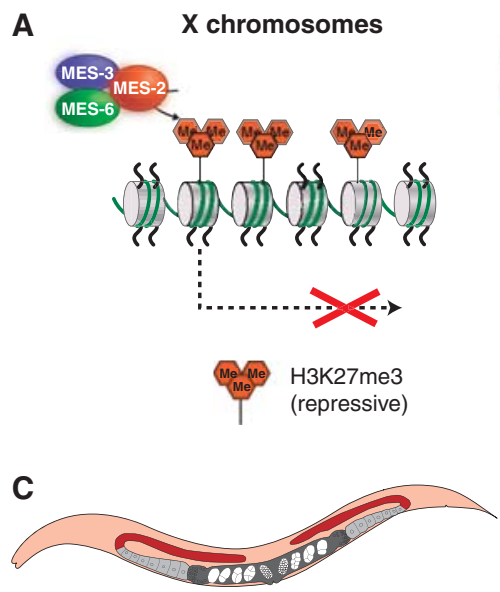

MES-4 methylates H3K36 on genes expressed in the germline.
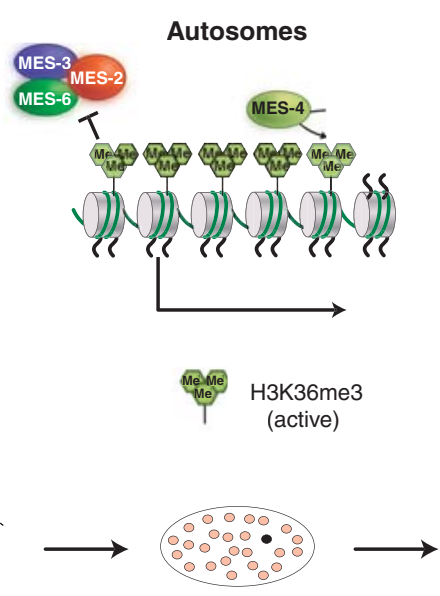

MES-4 propagates methylation of these genes in the absence of transcription.
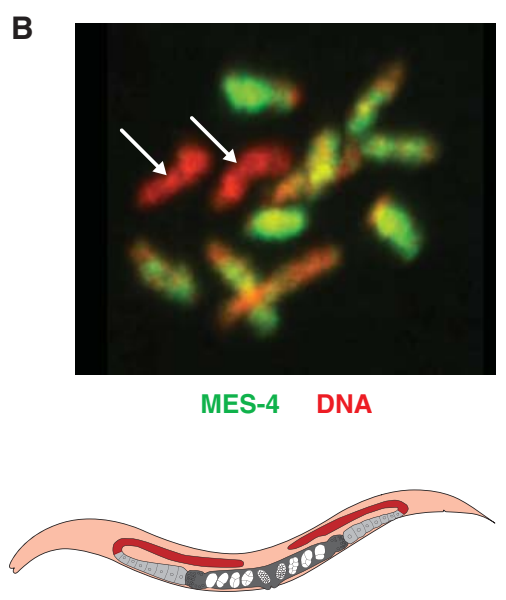

Correct set of genes is expressed in the germline and methylated by MES-4.

Figure 9. Model for the transgenerational role of MES-4 and how MES- 4 and MES-2/3/6 participate in X repression in the germline. (A) MES-2/3/6-generated $\mathrm{H} 3 \mathrm{~K} 27 \mathrm{me} 3$, a repressive histone modification, is concentrated on the $\mathrm{X}$ chromosomes. MES-4 and H3K36 methylation on autosomal genes repel the MES-2/3/6 complex, helping to concentrate its repressive action on the X chromosomes. (B) MES-4 is concentrated on the autosomes. MES-4 immunostaining is in green. DNA is stained red. Arrows mark the two X chromosomes, which lack MES-4 staining. (C) MES-4 associates with genes expressed in the maternal germline and marks them with H3K36me2/3. MES-4 propagation of $\mathrm{H} 3 \mathrm{~K} 36$ methyl marks in the absence of transcription enables MES-4 to transmit the memory of germline gene expression across generations.

perhaps directly, in repressing the $\mathrm{X}$ chromosomes in the germline of worms. Indeed, derepression of the two Xs is proposed to be the cause of germline degeneration observed in XX progeny of mes mutant mothers because $\mathrm{XO}$ progeny of those same mothers can be fertile, perhaps because derepression of a single $\mathrm{X}$ is tolerated during germline development, or more likely because another mechanism, such as heterochromatinization of the single $\mathrm{X}$ through MSUC, maintains repression in the XO germline (Garvin et al. 1998). It is interesting to note that, similar to the involvement of MES-2 and MES-6 in germline X repression in C. elegans, the vertebrate homologs of MES-2 and MES- 6 are involved in somatic X inactivation in XX mammals (see Brockdorff and Turner 2014; Grossniklaus and Paro 2014).

The fourth MES protein involved in X repression in the germline is MES-4. Its distribution by immunostaining is novel among chromosome-associated proteins and exactly opposite to what might be expected. In contrast to the other MES proteins, MES-4 associates with the five autosomes in a banded pattern and is strikingly absent from most of the length of the X chromosome (Fig. 9B) (Fong et al. 2002). MES-4, like MES-2, contains a SET domain and also has HKMT activity (Bender et al. 2006). It is responsible for $\mathrm{H} 3 \mathrm{~K} 36 \mathrm{me} 2$ and contributes to H3K36me3 in the germline and embryos. As predicted by the autosomal concentration of MES-4, H3K36 methylation is also dramatically concentrated on the autosomes. Recent analysis of the distributions of MES-4, H3K36 methyl marks, and RNA polymerase II by chromatin immunoprecipitation in embryos provided insights into how MES-4 is targeted to the autosomes and what role it serves there (Furuhashi et al. 2010; Rechtsteiner et al. 2010). In embryos, MES- 4 and $\mathrm{H} 3 \mathrm{~K} 36 \mathrm{me} 2 / 3$ reside in the body of genes that share the property of having been expressed in the maternal germline. Those genes include ubiquitously expressed genes, and germline-specific genes that were expressed in the maternal germline but are not expressed during embryogenesis and thus lack RNA polymerase II in embryos. The latter category revealed that MES4 can associate with genes independently of RNA polymerase II, which distinguishes it from other H3K36 HKMTs. The picture that has emerged is that MES-4 is a maintenance HKMT whose function is to propagate the memory of germline gene expression from the parental germline to the germline in progeny (Fig. 9C). Thus, MES-4 serves a truly epigenetic role, by transmitting a chromatin mark (H3K36me) across generations. This function is critical for germ cell survival. The concentration of MES- 4 on the autosomes is likely explained by MES-4's association with germline-expressed genes, which are concentrated on the autosomes and nearly absent from the $\mathrm{X}$, as discussed in Section 7. 
MES-4's participation in repressing the $\mathrm{X}$ chromosome emerged from transcript profiling of germlines dissected from fertile mes-4 mutant mothers (Bender et al. 2006; Gaydos et al. 2012). The primary change in gene expression was up-regulation of genes on the X. How does MES-4, which is concentrated on the autosomes, participate in repressing genes on the $\mathrm{X}$ ? The current model is that MES-4mediated H3K36 methylation of germline-expressed genes on the autosomes repels MES-2/3/6 from those genes and helps concentrate its repressive activity on other regions of the genome, including the X chromosomes (Fig. 9A). The main evidence for this model is the finding that loss of MES-4 from germline genes causes H3K27me3 to spread to germline genes and results in reduced $\mathrm{H} 3 \mathrm{~K} 27 \mathrm{me} 3$ on the $\mathrm{X}$ chromosome (Gaydos et al. 2012). In fact, in genomewide chromatin immunoprecipitation studies in diverse species, H3K36me3 and H3K27me3 generally occupy nonoverlapping regions of the genome, consistent with those marks excluding each other and defining distinct genomic regions (Kharchenko et al. 2011a; Liu et al. 2011; Gaydos et al. 2012). Furthermore, the notion that H3K36 methylation antagonizes $\mathrm{H} 3 \mathrm{~K} 27$ methylation is supported by the finding that prior methylation of $\mathrm{H} 3 \mathrm{~K} 36$ prevents methylation of K27 on the same histone tails in vitro (Schmitges et al. 2011; Yuan et al. 2011). The model presented for MES-4 participation in X repression in worms (Fig. 9A) is similar to the model for Dot1 participation in telomeric silencing in Saccharomyces cerevisiae (van Leeuwen and Gottschling 2002). Dot1-mediated methylation of H3K79 along chromosomes is thought to repel the Sir repressors and help focus their action on the telomeres. Loss of Dot1 allows spreading of the Sirs from telomeres and results in telomeric desilencing. MES-4 and Dot1 illustrate how histone modifiers can contribute to proper distributions of repressors by antagonizing promiscuous repressor binding (van Leeuwen and Gottschling 2002).

The MES proteins function epigenetically in two intertwined but conceptually distinct manners: regulation of histone modifications and chromatin states, as described in the preceding paragraphs, and maternal-effect regulation. A maternal-effect mutation is defined as one whose mutant phenotype is not revealed in first-generation homozygous mutants, but instead shows up in their progeny. In the case of first-generation mes/mes mutants, the presence of some wild-type MES product produced by the mes/+ mother and packaged into the oocyte is sufficient for the proper expansion of the two primordial germ cells into over a thousand functional germ cells in adults. The germ cells in these fertile mes/mes worms, however, cannot produce functional MES product for their offspring. As a result, in these offspring, the primordial germ cells undergo little proliferation and degenerate. The HKMTactivities encoded by mes- 2 and mes- 4 must establish a heritable chromatin state that is properly maintained in the many descendants of the two initial primordial germ cells. MES-2, MES-3, and MES-6 operate in a complex to concentrate a repressive chromatin modification (H3K27me3) on the X chromosomes in the germline, and participate, probably directly, in X repression. MES-4 participates in X repression from a distance by methylating H3K36 on germline-expressed genes on the autosomes, which repels and helps focus the activity of the MES-2/3/6 complex and H3K27me3 on the X. The MES system is thought to act epigenetically in the mother's germline and in early embryos to establish chromatin domains that are properly marked for subsequent expression (autosomal regions) or repression (the $\mathrm{X}$ chromosomes) during germline development in larvae (see Fig. 9A,C). Loss of the MES system leads to germline death and sterility, likely due, at least in part, to derepression of the $\mathrm{X}$ chromosomes.

The discussion thus far has focused on factors and mechanisms involved in repressing expression of X-linked genes in the germline. Intriguingly, several members of the C. elegans DRM complex appear to be involved in promoting what little expression of X-linked genes does occur in the germline. The DRM complex includes the worm homologs of Retinoblastoma, E2F, DP, and LIN-54/Mip120. The complex is named for DP, Retinoblastoma, and MybMuvB and is related to the mammalian DREAM complex. Loss of any of the C. elegans DRM proteins causes genes on the $\mathrm{X}$ to be down-regulated in the germline (Tabuchi et al. 2011). Like MES-4, DRM components appear, by immunostaining, to be concentrated on the autosomes in germ cells, leading to the model that like MES-4, DRM indirectly regulates transcription of genes on the X. An interesting possibility is that MES- 4 and DRM antagonistically influence transcription of germline-expressed genes on the autosomes, and as a result have opposite effects on transcription of genes on the $\mathrm{X}$ (Tabuchi et al. 2011).

\section{PATERNAL X INACTIVATION IN EARLY EMBRYOS}

The genomes contributed by the different gametes arrive in the zygote with vastly different epigenetic histories (Figs. 8 and 10). Although the X chromosome is inactive in early germ cell stages in both sexes (e.g., Fig. 10-nascent germline and mitosis stages), the $\mathrm{X}$ becomes transcriptionally active during the late pachytene stage of oogenesis (e.g., Figs. 8 and 10-oogenesis) (Fong et al. 2002; Kelly et al. 2002). In contrast, during spermatogenesis in both hermaphrodites and males the $\mathrm{X}$ is never activated (e.g., Figs. 8 and 10-spermatogenesis), undergoes premature condensation, and in XO meiosis is additionally enriched in 


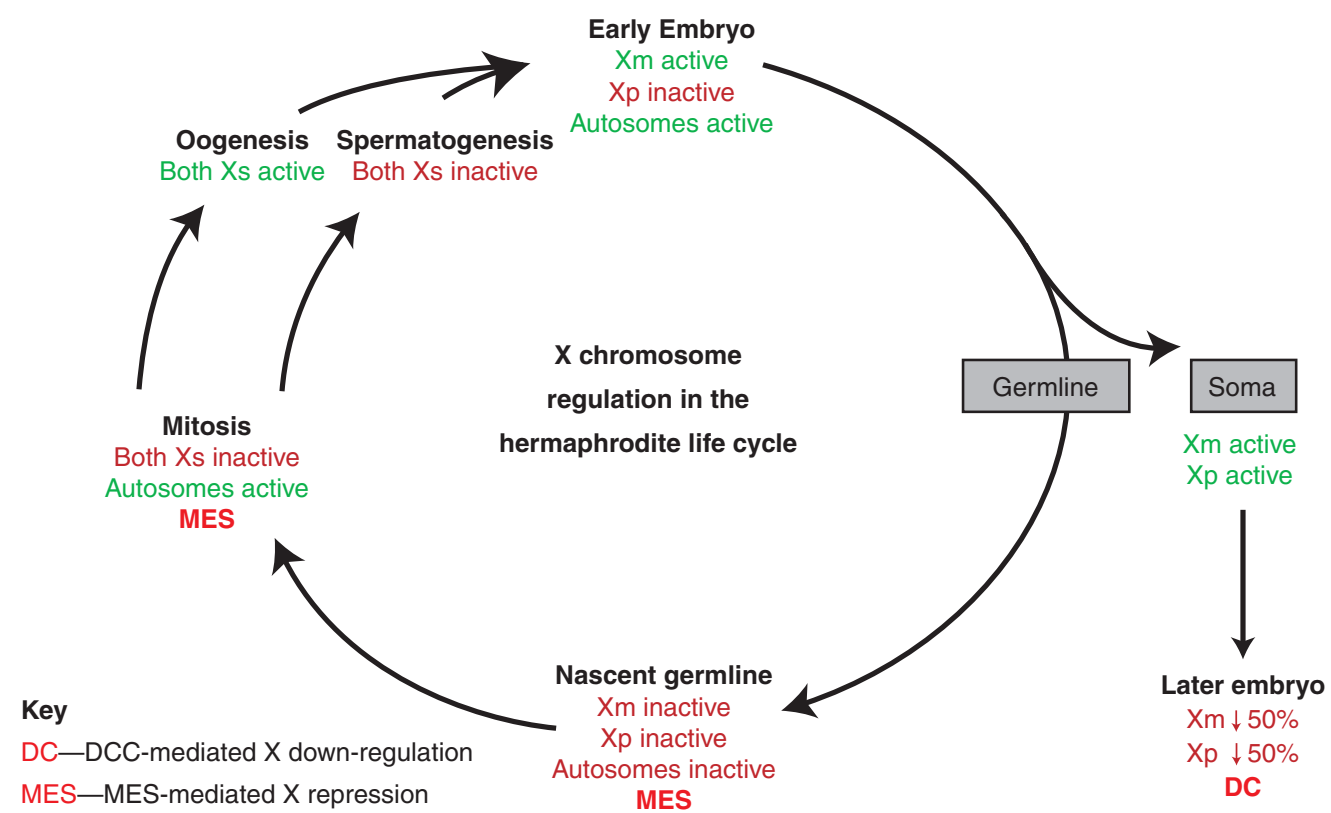

Figure 10. Regulation of the X chromosomes through the life cycle of an XX hermaphrodite. The X chromosomes are regulated by different mechanisms at different stages and in different tissues: paternal $\mathrm{X}$ inactivation in the early embryo, dosage compensation (DC) in the somatic tissues of 30-cell and later-stage embryos and worms, and MESmediated repression in the germline. In XO male meiosis (not depicted), meiotic silencing of the unsynapsed X by MSUC additionally occurs in the germline.

H3K9me2 (Fig. 8) (Kelly et al. 2002; Bean et al. 2004). During sperm formation, although some canonical histones are replaced by specialized, sperm-specific histone variants and protamine-like basic proteins (Chu et al. 2006), the sperm genome possesses and enters the egg with easily detectable levels of histone $\mathrm{H} 3$ and several histone modifications, including $\mathrm{H} 3 \mathrm{~K} 4 \mathrm{me} 2$, on the autosomes (Arico et al. 2011). The oocyte chromatin also continues to show significant levels of most activating histone modifications even during chromosome condensation in diakinesis (Fig. 8). RNA polymerase II levels associated with DNA drop precipitously in diakinesis-stage oocytes, suggesting that the histone modifications retained by the chromatin reflect recent transcriptional history instead of ongoing transcriptional activity (Kelly et al. 2002). Thus, the zygote inherits two epigenetically different genomes and, in particular, two X chromosomes with very different transcriptional histories-a recently active, oocyte-derived Xm and a sperm-derived $\mathrm{Xp}$ with little or no recent transcriptional activity.

After entry into the oocyte, the sperm DNA displays histone modifications such as H3K4me2 (Arico et al. 2011) as it begins to decondense to form the sperm pronucleus. In striking contrast to the autosomes, the decondensing Xp lacks H3K4me2 and histone H3 acetylation (Bean et al. 2004). There is, however, no difference in histone $\mathrm{H} 4$ modifications between the $\mathrm{Xp}$ and the autosomes.
In the oocyte pronucleus, all chromosomes, including the $\mathrm{Xm}$, are similarly modified and remain so throughout embryogenesis. Intriguingly, the $\mathrm{Xp}$-specific absence of $\mathrm{H} 3$ modifications is maintained after DNA replication and survives multiple rounds of DNA replication and cell division, and thus has been termed an "epigenetic imprint." However, the imprint is gradually lost; that is, $\mathrm{H} 3$-specific modifications become increasingly detectable on the Xp until there are no obvious differences in $\mathrm{H} 3 \mathrm{~K} 4 \mathrm{me} 2$ levels between the Xp and other chromosomes. An attractive scenario is that the absence of $\mathrm{H} 3 \mathrm{~K} 4 \mathrm{me} 2$ and other marks of active chromatin from the $\mathrm{Xp}$ in early embryos reflects the transcriptionally silent state of the Xp during spermatogenesis (Figs. 8 and 10), and the Xp acquires marks of active chromatin as transcription from the zygotic genome is activated. It is noteworthy that maternally supplied H3.3, an $\mathrm{H} 3$ variant associated with active gene expression, exchanges onto the $\mathrm{Xp}, \mathrm{Xm}$, and the autosomes upon fertilization, yet it fails to acquire active histone modifications specifically on Xp (Ooi et al. 2006; Arico et al. 2011).

The Xp imprint in XX embryos is detected in both cross-progeny (from XO-derived sperm) and self-progeny (from XX-derived sperm). The pairing status of the X chromosome during spermatogenesis, and thus $\mathrm{H} 3 \mathrm{~K} 9 \mathrm{me} 2$ targeting and enrichment on the $\mathrm{X}$, therefore does not play an obvious role in establishment of the Xp imprint. However, the stability of the imprint-that is, the number of cell 
divisions after which it can still be readily observed-is significantly increased in offspring from XO-derived sperm relative to XX-derived sperm (Bean et al. 2004). Therefore, heterochromatin assembly on unpaired DNA during meiosis has effects that persist through early embryonic stages. Importantly, both pairing-based meiotic silencing and imprinted $\mathrm{Xp}$ inactivation are also observed in mammals, as discussed in Brockdorff and Turner (2014).

Genetic imprinting (covered in detail in Barlow and Bartolomei 2014) has long been thought to be absent in C. elegans, as animals with uniparental inheritance of any single chromosome are viable and fertile (Hodgkin et al. 1979; Haack and Hodgkin 1991). In particular, there are no reported deleterious consequences of patriclinous inheritance of the X (i.e., XpXp animals). The unique genetic composition of the $\mathrm{X}$ chromosome, however, may help to explain why uniparental inheritance is not detrimental in C. elegans. In addition to a paucity of germline-expressed loci on the $\mathrm{X}$ chromosome, genes encoding early zygotic transcripts and those required for early embryonic development are also strikingly underrepresented on the X (Piano et al. 2000; Baugh et al. 2003). Thus, most genes whose products are essential for the very early stages during which the $\mathrm{Xp}$ is inactive are unlikely to reside on the $\mathrm{X}$, rendering $\mathrm{X}$-specific uniparental inheritance inconsequential in genetic tests.

Xp inactivation does, however, suggest a reason why somatic dosage compensation is not fully active in early embryos. The assembly of DCC components on the X chromosomes in XX embryos is not detectable by antibody staining until approximately the 30 -cell stage. This is shortly after the Xp becomes fully decorated with $\mathrm{H} 3$ modifications, and is thus presumably fully activated. Activation of somatic dosage compensation is responsive to levels of the XSEs, the X-linked products that comprise the X portion of the X:A ratio, as discussed in Section 2. Full or partial repression of these elements on the $\mathrm{Xp}$ may render the early embryo functionally XO (i.e., the X:A is interpreted as 0.5 ). As the $\mathrm{Xp}$ reactivates with increased rounds of cell division, the level of $\mathrm{X}$ transcription may finally reach the critical threshold at which a two X-chromosome dosage is sensed and X:A equals 1, triggering the dosage compensation cascade. One might consider this a switch from maternal/paternal control of dosage compensation to zygotic control.

\section{CONCLUDING REMARKS}

C. elegans is one among many animals that uses a chromosome-based mechanism of sex determination in which the two sexes have a different number of $\mathrm{X}$ chromosomes. Interestingly, the germline and soma in worms have evolved distinct mechanisms to deal with this difference in X ploidy. In the somatic tissues, a conserved complex that is normally used for chromatin condensation and segregation during mitosis and meiosis appears to have been co-opted and adapted to achieve twofold repression of both X chromosomes in XX animals. This complex is recruited to the $\mathrm{X}$ chromosome in part by specific DNA sequences, and spreads along the $\mathrm{X}$ via a sequence-independent mechanism. Although it is conceptually attractive to envisage that an "inefficient" condensin complex might serve to decrease transcriptional efficiency, whether the complex acts locally at the level of individual genes, or at a distance across the entire $\mathrm{X}$, and how repression is limited to twofold are currently not understood. This somatic dosage compensation mechanism appears to have been superimposed on a separate genome-wide dosage balancing process that compensates for $\mathrm{X}$ aneuploidy by up-regulating all expressed X-linked genes in both sexes by a factor of 2 . The mechanism by which this second process operates is not understood.

In the germline, the $\mathrm{X}$ chromosomes are globally repressed during early stages of germ cell development in $\mathrm{XX}$ animals and during all stages of germ cell development in XO animals. Silencing of the single X chromosome in males, a mechanism to protect the integrity of unpaired chromosomal segments, likely created strong evolutionary pressure to move genes required for germ cell maturation off of the X chromosome, and also to repress the two X chromosomes in hermaphrodites. Global X-chromosome repression in the germline of $\mathrm{XO}$ and $\mathrm{XX}$ animals, in fact, is also one mechanism to compensate for the $\mathrm{X}$-dosage difference between the sexes. If some X-linked genes that operate in both sexes escape repression, then the question arises as to whether the germline equalizes their expression in XX versus $\mathrm{XO}$ animals. The answer to this is not known. Equalization in the germline would involve a mechanism other than the DCC that operates in somatic tissues.

The germline and soma differ in many fundamental ways. This article highlights the different mechanisms of $\mathrm{X}$-chromosome regulation in the germline and soma. One interesting theme that has emerged is co-option of different preexisting mechanisms, including utilization of a condensin-related complex to subtly down-regulate X expression in the soma, and utilization of a PRC2-related complex to repress the Xs in the germline. The heterochromatinization of the single $\mathrm{X}$ in males is thought to have dramatically altered the representation of genes on the $\mathrm{X}$, such that genes required for general germline functions and early embryonic development are significantly underrepresented on this chromosome. The $\mathrm{X}$ chromosome and its regulation in C. elegans provide a window into chromosome-wide gene regulation mechanisms and genome evolution. 


\section{REFERENCES}

${ }^{*}$ Reference is also in this collection.

Alekseyenko AA, Kuroda MI. 2004. Molecular biology. Filling gaps in genome organization. Science 303: 1148-1149.

* Aramayo R, Selker EU. 2013. Neurospora crassa, a model system for epigenetics research. Cold Spring Harb Perspect Biol 5: a017921.

Arico JK, Katz DJ, van der Vlag J, Kelly WG. 2011. Epigenetic patterns maintained in early Caenorhabditis elegans embryos can be established by gene activity in the parental germ cells. PLoS Genet 7: e1001391.

Baarends WM, Wassenaar E, van der Laan R, Hoogerbrugge J, SleddensLinkels E, Hoeijmakers JH, de Boer P, Grootegoed JA. 2005. Silencing of unpaired chromatin and histone H2A ubiquitination in mammalian meiosis. Mol Cell Biol 25: 1041-1053.

* Barlow DP, Bartolomei MS. 2014. Genomic imprinting in mammals. Cold Spring Harb Perspect Biol doi: 10.1101cshperspect.a018382.

Baugh LR, Hill AA, Slonim DK, Brown EL, Hunter CP. 2003. Composition and dynamics of the Caenorhabditis elegans early embryonic transcriptome. Development 130: 889-900.

Bean CJ, Schaner CE, Kelly WG. 2004. Meiotic pairing and imprinted X chromatin assembly in Caenorhabditis elegans. Nat Genet 36: 100105.

Bender LB, Cao R, Zhang Y, Strome S. 2004. The MES-2/MES-3/MES-6 complex and regulation of histone $\mathrm{H} 3$ methylation in C. elegans. Curr Biol 14: 1639-1643.

Bender LB, Suh J, Carroll CR, Fong Y, Fingerman IM, Briggs SD, Cao R, Zhang Y, Reinke V, Strome S. 2006. MES-4: An autosome-associated histone methyltransferase that participates in silencing the X chromosomes in the C. elegans germline. Development 133: 3907-3917.

Bessler JB, Andersen EC, Villeneuve AM. 2010. Differential localization and independent acquisition of the H3K9me2 and H3K9me3 chromatin modifications in the Caenorhabditis elegans adult germline. PLoS Genet 6: e1000830.

* Brockdorff N, Turner B. 2014. Dosage compensation in mammals. Cold Spring Harb Perspect Biol doi: 10.1101/cshperspect.a019406.

Carmi I, Kopczynski JB, Meyer BJ. 1998. The nuclear hormone receptor SEX-1 is an X-chromosome signal that determines nematode sex. Nature 396: $168-173$.

Chu DS, Dawes HE, Lieb JD, Chan RC, Kuo AF, Meyer BJ. 2002. A molecular link between gene-specific and chromosome-wide transcriptional repression. Genes Dev 16: 796-805.

Chu DS, Liu H, Nix P, Wu TF, Ralston EJ, Yates JR III, Meyer BJ. 2006. Sperm chromatin proteomics identifies evolutionarily conserved fertility factors. Nature 443: 101-105.

Chua G, Morris QD, Sopko R, Robinson MD, Ryan O, Chan ET, Frey BJ, Andrews BJ, Boone C, Hughes TR. 2006. Identifying transcription factor functions and targets by phenotypic activation. Proc Natl Acad Sci 103: 12045-12050.

Conrad T, Cavalli FM, Vaquerizas JM, Luscombe NM, Akhtar A. 2012. Drosophila dosage compensation involves enhanced Pol II recruitment to male X-linked promoters. Science 337: 742-746.

Cowell IG, Aucott R, Mahadevaiah SK, Burgoyne PS, Huskisson N, Bongiorni S, Prantera G, Fanti L, Pimpinelli S, Wu R, et al. 2002. Heterochromatin, HP1 and methylation at lysine 9 of histone H3 in animals. Chromosoma 111: 22-36.

Csankovszki G, McDonel P, Meyer BJ. 2004. Recruitment and spreading of the C. elegans dosage compensation complex along X chromosomes. Science 303: 1182-1185.

Csankovszki G, Collette K, Spahl K, Carey J, Snyder M, Petty E, Patel U, Tabuchi T, Liu H, McLeod I, et al. 2009. Three distinct condensin complexes control C. elegans chromosome dynamics. Curr Biol 19: 9-19.

Dawes HE, Berlin DS, Lapidus DM, Nusbaum C, Davis TL, Meyer BJ. 1999. Dosage compensation proteins targeted to X chromosomes by a determinant of hermaphrodite fate. Science 284: 1800-1804.
Deng X, Hiatt JB, Nguyen DK, Ercan S, Sturgill D, Hillier LW, Schlesinger F, Davis CA, Reinke VJ, Gingeras TR, et al. 2011. Evidence for compensatory upregulation of expressed X-linked genes in mammals, Caenorhabditis elegans and Drosophila melanogaster. Nat Genet 43: $1179-1185$.

Ercan S, Lieb JD. 2009. C elegans dosage compensation: A window into mechanisms of domain-scale gene regulation. Chromosome Res 17: 215-227.

Ercan S, Giresi PG, Whittle CM, Zhang X, Green RD, Lieb JD. 2007. X chromosome repression by localization of the C. elegans dosage compensation machinery to sites of transcription initiation. Nat Genet 39: 403-408.

Ercan S, Dick LL, Lieb JD. 2009. The C. elegans dosage compensation complex propagates dynamically and independently of X chromosome sequence. Curr Biol 19: 1777-1787.

Ercan S, Lubling Y, Segal E, Lieb JD. 2011. High nucleosome occupancy is encoded at X-linked gene promoters in C. elegans. Genome Res 21: 237-244.

Fong Y, Bender L, Wang W, Strome S. 2002. Regulation of the different chromatin states of autosomes and X chromosomes in the germline of C. elegans. Science 296: 2235-2238.

Furuhashi H, Takasaki T, Rechtsteiner A, Li T, Kimura H, Checchi PM, Strome S, Kelly WG. 2010. Trans-generational epigenetic regulation of C. elegans primordial germ cells. Epigenetics Chromatin 3: 15.

Gao F, Foat BC, Bussemaker HJ. 2004. Defining transcriptional networks through integrative modeling of mRNA expression and transcription factor binding data. BMC Bioinformatics 5: 31.

Garvin C, Holdeman R, Strome S. 1998. The phenotype of mes-2, mes-3, mes-4 and mes-6, maternal-effect genes required for survival of the germline in Caenorhabditis elegans, is sensitive to chromosome dosage. Genetics 148: 167-185.

Gaydos L, Rechtsteiner A, Egelhofer T, Carroll C, Strome S. 2012. Antagonism between MES-4 and Polycomb repressive complex 2 promotes appropriate gene expression in C. elegans germ cells. Cell Rep 2: 11691177.

Gladden JM, Meyer BJ. 2007. A ONECUT homeodomain protein communicates X chromosome dose to specify Caenorhabditis elegans sexual fate by repressing a sex switch gene. Genetics 177: 1621-1637.

Gladden JM, Farboud B, Meyer BJ. 2007. Revisiting the X:A signal that specifies Caenorhabditis elegans sexual fate. Genetics 177: 1639-1654.

Goldstein P, Slaton DE. 1982. The synaptonemal complexes of Caenorhabditis elegans: Comparison of wild-type and mutant strains and pachytene karyotype analysis of wild-type. Chromosoma 84: 585-597.

* Grossniklaus U, Paro R. 2014. Transcriptional silencing by Polycomb group proteins. Cold Spring Harb Perspect Biol doi: 10.1101/ cshperspect.a019331.

Haack H, Hodgkin J. 1991. Tests for parental imprinting in the nematode Caenorhabditis elegans. Mol Gen Genet 228: 482-485.

Handel MA. 2004. The XY body: A specialized meiotic chromatin domain. Exp Cell Res 296: 57-63.

Hansen D, Hubbard EJ, Schedl T. 2004. Multi-pathway control of the proliferation versus meiotic development decision in the Caenorhabditis elegans germline. Dev Biol 268: 342-357.

Hirano T. 2002. The ABCs of SMC proteins: Two-armed ATPases for chromosome condensation, cohesion, and repair. Genes Dev 16: 399-414.

Hodgkin J, Horvitz HR, Brenner S. 1979. Nondisjunction mutants of the nematode Caenorhabditis elegans. Genetics 91: 67-94.

Hu Z, Killion PJ, Iyer VR. 2007. Genetic reconstruction of a functional transcriptional regulatory network. Nat Genet 39: 683-687.

Jans J, Gladden JM, Ralston EJ, Pickle CS, Michel AH, Pferdehirt RR, Eisen MB, Meyer BJ. 2009. A condensin-like dosage compensation complex acts at a distance to control expression throughout the genome. Genes Dev 23: 602-618.

Karachentsev D, Sarma K, Reinberg D, Steward R. 2005. PR-Set7-dependent methylation of histone H4 Lys 20 functions in repression of gene expression and is essential for mitosis. Genes Dev 19: 431-435. 


\section{S. Strome et al.}

Kelly WG, Aramayo R. 2007. Meiotic silencing and the epigenetics of sex. Chromosome Res 15: 633-651.

Kelly WG, Schaner CE, Dernburg AF, Lee M-H, Kim SK, Villeneuve AM, Reinke V. 2002. X-chromosome silencing in the germline of C. elegans. Development 129: 479-492.

Ketel CS, Andersen EF, Vargas ML, Suh J, Strome S, Simon JA. 2005. Subunit contributions to histone methyltransferase activities of fly and worm polycomb group complexes. Mol Cell Biol 25: 6857-6868.

Kharchenko PV, Alekseyenko AA, Schwartz YB, Minoda A, Riddle NC, Ernst J, Sabo PJ, Larschan E, Gorchakov AA, Gu T, et al. 2011a. Comprehensive analysis of the chromatin landscape in Drosophila melanogaster. Nature 471: 480-485.

Kharchenko PV, Xi R, Park PJ. 2011b. Evidence for dosage compensation between the X chromosome and autosomes in mammals. Nat Genet 43: 1167-1169; author reply 1171-1172.

* Kuroda M, Lucchesi J. 2014. Dosage compensation in Drosophila. Cold Spring Harb Perspect Biol doi: 10.1101/cshperspect.a019398.

Larschan E, Bishop EP, Kharchenko PV, Core LJ, Lis JT, Park PJ, Kuroda MI. 2011. X chromosome dosage compensation via enhanced transcriptional elongation in Drosophila. Nature 471: 115-118.

Lieb JD, de Solorzano CO, Rodriguez EG, Jones A, Angelo M, Lockett S, Meyer BJ. 2000. The Caenorhabditis elegans dosage compensation machinery is recruited to $\mathrm{X}$ chromosome DNA attached to an autosome. Genetics 156: 1603-1621.

Liu W, Tanasa B, Tyurina OV, Zhou TY, Gassmann R, Liu WT, Ohgi KA, Benner C, Garcia-Bassets I, Aggarwal AK, et al. 2010. PHF8 mediates histone H4 lysine 20 demethylation events involved in cell cycle progression. Nature 466: 508-512.

Liu T, Rechtsteiner A, Egelhofer TA, Vielle A, Latorre I, Cheung MS, Ercan S, Ikegami K, Jensen M, Kolasinska-Zwierz P, et al. 2011. Broad chromosomal domains of histone modification patterns in C. elegans. Genome Res 21: 227-236.

Maciejowski J, Ahn JH, Cipriani PG, Killian DJ, Chaudhary AL, Lee JI, Voutev R, Johnsen RC, Baillie DL, Gunsalus KC, et al. 2005. Autosomal genes of autosomal/X-linked duplicated gene pairs and germ-line proliferation in Caenorhabditis elegans. Genetics 169: 19972011.

Maine EM, Hauth J, Ratliff T, Vought VE, She X, Kelly WG. 2005. EGO-1, a putative RNA-dependent RNA polymerase, is required for heterochromatin assembly on unpaired DNA during C. elegans meiosis. Curr Biol 15: $1972-1978$.

* Martienssen R, Moazed D. 2014. RNAi and heterochromatin assembly. Cold Spring Harb Perspect Biol doi: 10.1101/cshperspect.a019323.

McDonel P, Jans J, Peterson BK, Meyer BJ. 2006. Clustered DNA motifs mark X chromosomes for repression by a dosage compensation complex. Nature 444: 614-618.

Meyer BJ. 1997. Sex determination and X chromosome dosage compensation. In C. elegans II (ed. Riddle DL, et al.), pp. 209-240. Cold Spring Harbor Laboratory Press, Cold Spring Harbor, NY.

Meyer BJ. 2000. Sex in the wormcounting and compensating X-chromosome dose. Trends Genet 16: 247-253.

Meyer BJ. 2005. X-chromosome dosage compensation. In WormBook, ed. The C. elegans Research Community, Wormbook, doi/10.1895/ wormbook.1.7.1, http://www.wormbook.org.

Nicoll M, Akerib CC, Meyer BJ. 1997. X-chromosome-counting mechanisms that determine nematode sex. Nature 388: 200-204.

Nigon V. 1951. Polyploidie experimentale chez un nematode libre, Rhaditis elegans maupas. Bull Biol Fr Belg 85: 187-255.

Ohno S. 1967. Sex chromosomes and sex-linked genes. Springer, Berlin.

Ooi SL, Priess JR, Henikoff S. 2006. Histone H3.3 variant dynamics in the germline of Caenorhabditis elegans. PLoS Genet 2: e97.

Petty EL, Collette KS, Cohen AJ, Snyder MJ, Csankovszki G. 2009. Restricting dosage compensation complex binding to the $\mathrm{X}$ chromosomes by H2A.Z/HTZ-1. PLoS Genet 5: e1000699.

Pferdehirt RR, Kruesi WS, Meyer BJ. 2011. An MLL/COMPASS subunit functions in the C. elegans dosage compensation complex to target $\mathrm{X}$ chromosomes for transcriptional regulation of gene expression. Genes Dev 25: 499-515.

Piano F, Schetter AJ, Mangone M, Stein L, Kemphues KJ. 2000. RNAi analysis of genes expressed in the ovary of Caenorhabditis elegans. Curr Biol 10: 1619-1622.

Powell JR, Jow MM, Meyer BJ. 2005. The T-box transcription factor SEA1 is an autosomal element of the X:A signal that determines C. elegans sex. Dev Cell 9: 339-349.

Rechtsteiner A, Ercan S, Takasaki T, Phippen TM, Egelhofer TA, Wang W, Kimura H, Lieb JD, Strome S. 2010. The histone H3K36 methyltransferase MES- 4 acts epigenetically to transmit the memory of germline gene expression to progeny. PLoS Genet 6: e1001091.

Reddy KC, Villeneuve AM. 2004. C elegans HIM-17 links chromatin modification and competence for initiation of meiotic recombination. Cell 118: 439-452.

Reinke V, Smith HE, Nance J, Wang J, Van Doren C, Begley R, Jones SJM, Davis EB, Scherer S, Ward S, et al. 2000. A global profile of germline gene expression in C. elegans. Mol Cell 6: 605-616.

Reinke V, Gil IS, Ward S, Kazmer K. 2004. Genome-wide germline-enriched and sex-biased expression profiles in Caenorhabditis elegans. Development 131: 311-323.

Schedl T. 1997. Developmental genetics of the germline. In C elegans II (ed. Riddle DL, et al.), pp. 241-269. Cold Spring Harbor Laboratory Press, Cold Spring Harbor, NY.

Schmitges FW, Prusty AB, Faty M, Stutzer A, Lingaraju GM, Aiwazian J, Sack R, Hess D, Li L, Zhou S, et al. 2011. Histone methylation by PRC2 is inhibited by active chromatin marks. Mol Cell 42: 330-341.

She X, Xu X, Fedotov A, Kelly WG, Maine EM. 2009. Regulation of heterochromatin assembly on unpaired chromosomes during Caenorhabditis elegans meiosis by components of a small RNA-mediated pathway. PLoS Genet 5: e1000624.

Shiu PK, Raju NB, Zickler D, Metzenberg RL. 2001. Meiotic silencing by unpaired DNA. Cell 107: 905-916.

Skipper M, Milne CA, Hodgkin J. 1999. Genetic and molecular analysis of fox-1, a numerator element involved in Caenorhabditis elegans primary sex determination. Genetics 151: 617-631.

Spencer WC, Zeller G, Watson JD, Henz SR, Watkins KL, McWhirter RD, Petersen S, Sreedharan VT, Widmer C, Jo J, et al. 2011. A spatial and temporal map of C. elegans gene expression. Genome Res 21:325341.

Tabuchi TM, Deplancke B, Osato N, Zhu LJ, Barrasa MI, Harrison MM, Horvitz HR, Walhout AJ, Hagstrom KA. 2011. Chromosome-biased binding and gene regulation by the Caenorhabditis elegans DRM complex. PLoS Genet 7: e1002074.

Turner JM. 2005. Sex chromosomes make their mark. Chromosoma 114: $300-306$.

Turner JM, Mahadevaiah SK, Fernandez-Capetillo O, Nussenzweig A, Xu X, Deng CX, Burgoyne PS. 2005. Silencing of unsynapsed meiotic chromosomes in the mouse. Nat Genet 37: 41-47.

van Leeuwen F, Gottschling DE. 2002. Genome-wide histone modifications: Gaining specificity by preventing promiscuity. Curr Opin Cell Biol 14: 756-762.

Vielle A, Lang J, Dong Y, Ercan S, Kotwaliwale C, Rechtsteiner A, Appert A, Chen Q, Dose A, Egelhofer T, et al. 2012. H4K20mel contributes to downregulation of X-linked genes for C. elegans dosage compensation. PLoS Genet 8: e1002933.

Wang X, Zhao Y, Wong K, Ehlers P, Kohara Y, Jones SJ, Marra MA, Holt RA, Moerman DG, Hansen D. 2009. Identification of genes expressed in the hermaphrodite germline of C. elegans using SAGE. BMC Genomics 10: 213.

Wells MB, Snyder MJ, Custer LM, Csankovszki G. 2012. Caenorhabditis elegans dosage compensation regulates histone $\mathrm{H} 4$ chromatin state on X chromosomes. Mol Cell Biol 32: 1710-1719.

Wu CI, Xu EY. 2003. Sexual antagonism and X inactivation-The SAXI hypothesis. Trends Genet 19: 243-247. 
Xiong Y, Chen X, Chen Z, Wang X, Shi S, Wang X, Zhang J, He X. 2010. RNA sequencing shows no dosage compensation of the active $\mathrm{X}$-chromosome. Nat Genet 42: 1043-1047.

Xu L, Fong Y, Strome S. 2001. The Caenorhabditis elegans maternal-effect sterile proteins, MES-2, MES- 3, and MES-6, are associated in a complex in embryos. Proc Natl Acad Sci 98: 5061-5066.

Yang H, Mizzen CA. 2009. The multiple facets of histone H4-lysine 20 methylation. Biochem Cell Biol 87: 151-161.

Yonker SA, Meyer BJ. 2003. Recruitment of C. elegans dosage compensation proteins for gene-specific versus chromosome-wide repression. Development 130: 6519-6532.
Yuan W, Xu M, Huang C, Liu N, Chen S, Zhu B. 2011. H3K36 methylation antagonizes PRC2-mediated H3K27 methylation. J Biol Chem 286: $7983-7989$.

\section{WWW RESOURCE}

http://www.wormbook.org/chapters/www_dosagecomp/dosagecomp.html Meyer BJ. 2005. X-chromosome dosage compensation. In WormBook. 


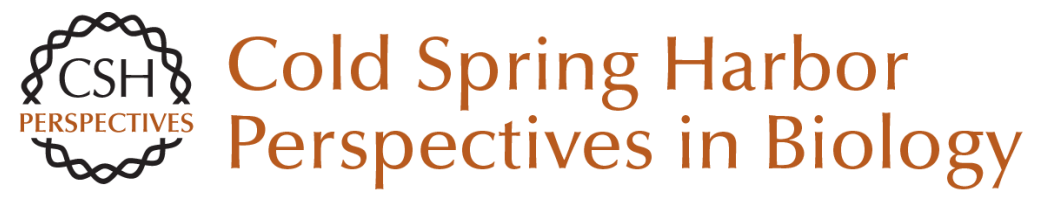

\section{Regulation of the X Chromosomes in Caenorhabditis elegans}

Susan Strome, William G. Kelly, Sevinc Ercan and Jason D. Lieb

Cold Spring Harb Perspect Biol 2014; doi: 10.1101/cshperspect.a018366

Subject Collection Epigenetics

Metabolic Signaling to Chromatin Shelley L. Berger and Paolo Sassone-Corsi

Histone and DNA Modifications as Regulators of Neuronal Development and Function Stavros Lomvardas and Tom Maniatis

Histone Modifications and Cancer James E. Audia and Robert M. Campbell

Epigenetics and Human Disease Huda Y. Zoghbi and Arthur L. Beaudet

Induced Pluripotency and Epigenetic Reprogramming Konrad Hochedlinger and Rudolf Jaenisch

Long-Range Chromatin Interactions Job Dekker and Tom Misteli

RNAi and Heterochromatin Assembly Robert Martienssen and Danesh Moazed

Dosage Compensation in Drosophila John C. Lucchesi and Mitzi I. Kuroda
Epigenetic Determinants of Cancer Stephen B. Baylin and Peter A. Jones

Maintenance of Epigenetic Information Geneviève Almouzni and Howard Cedar

A Structural Perspective on Readout of Epigenetic Histone and DNA Methylation Marks Dinshaw J. Patel

The Necessity of Chromatin: A View in

Perspective Vincenzo Pirrotta

Germline and Pluripotent Stem Cells Wolf Reik and M. Azim Surani

Comprehensive Catalog of Currently Documented Histone Modifications Yingming Zhao and Benjamin A. Garcia

Epigenetic Regulation of Chromatin States in Schizosaccharomyces pombe Robin C. Allshire and Karl Ekwall

Histone Variants and Epigenetics Steven Henikoff and M. Mitchell Smith

For additional articles in this collection, see http://cshperspectives.cshlp.org/cgi/collection/

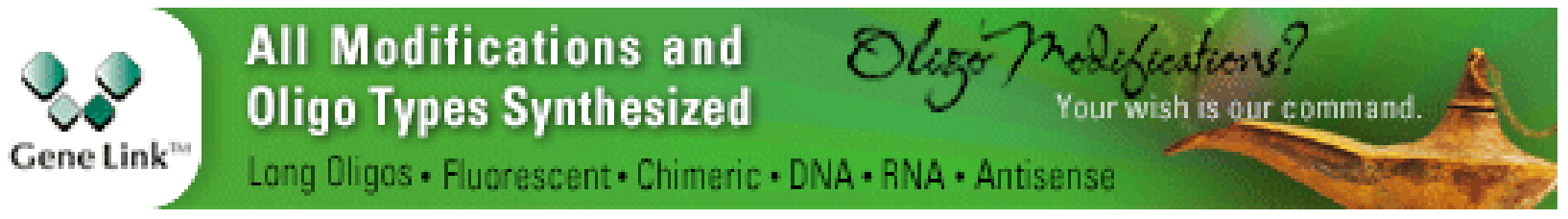

Copyright @ 2014 Cold Spring Harbor Laboratory Press; all rights reserved 
For additional articles in this collection, see http://cshperspectives.cshlp.org/cgi/collection/

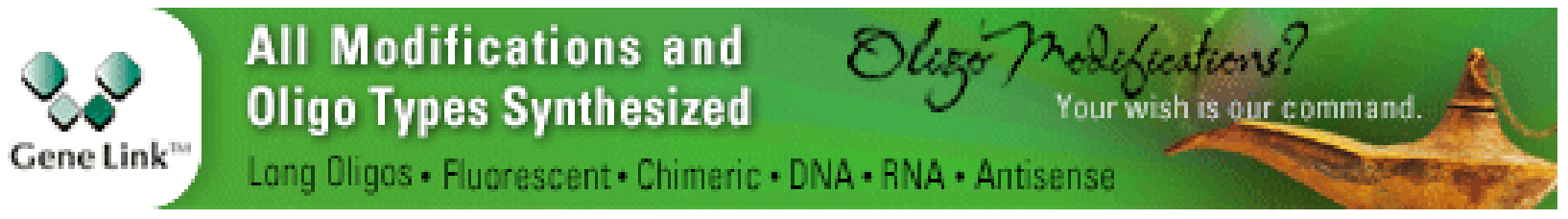

Copyright @ 2014 Cold Spring Harbor Laboratory Press; all rights reserved 